Supporting Information for

\title{
Mechanistic Study on the Origin of the Trans Selectivity in Alkyne Semihydrogenation by a Heterobimetallic Rhodium-Gallium Catalyst in a Metal-Organic Framework
}

\author{
Sai Puneet Desai ${ }^{\dagger}$, Jingyun Ye ${ }^{\dagger, \neq}$, Timur Islamoglu", Omar K. Farha, "Connie C. Lu ${ }^{\dagger}, *$
}

${ }^{\dagger}$ Department of Chemistry, and ${ }^{\ddagger}$ Chemical Theory Center, University of Minnesota, 207 Pleasant Street SE, Minneapolis, Minnesota 55455-0431, United States

"Department of Chemistry, Northwestern University, Evanston, Illinois 60208, United States

*email: clu@umn.edu 


\section{SI Table of Contents}

\section{Kinetics Studies}

Initial rate studies

$\mathrm{H}_{2} / \mathrm{D}_{2}$ scrambling studies

DFT-calculated structures of intermediates and transition states

DFT-calculated atomic charges, enthalpic barriers, and KIE values Eyring analysis

Alkyne binding study

Proposed mechanism and derivation of rate law

Isotope labeling studies with $Z$ - and $E$-stilbene
Page

number

S3

S5

S6

S7

S8

S9

$\mathrm{S} 10$

S1 1

S16

S22

S23 


\section{Kinetic Studies}

\section{Initial Rate Studies}

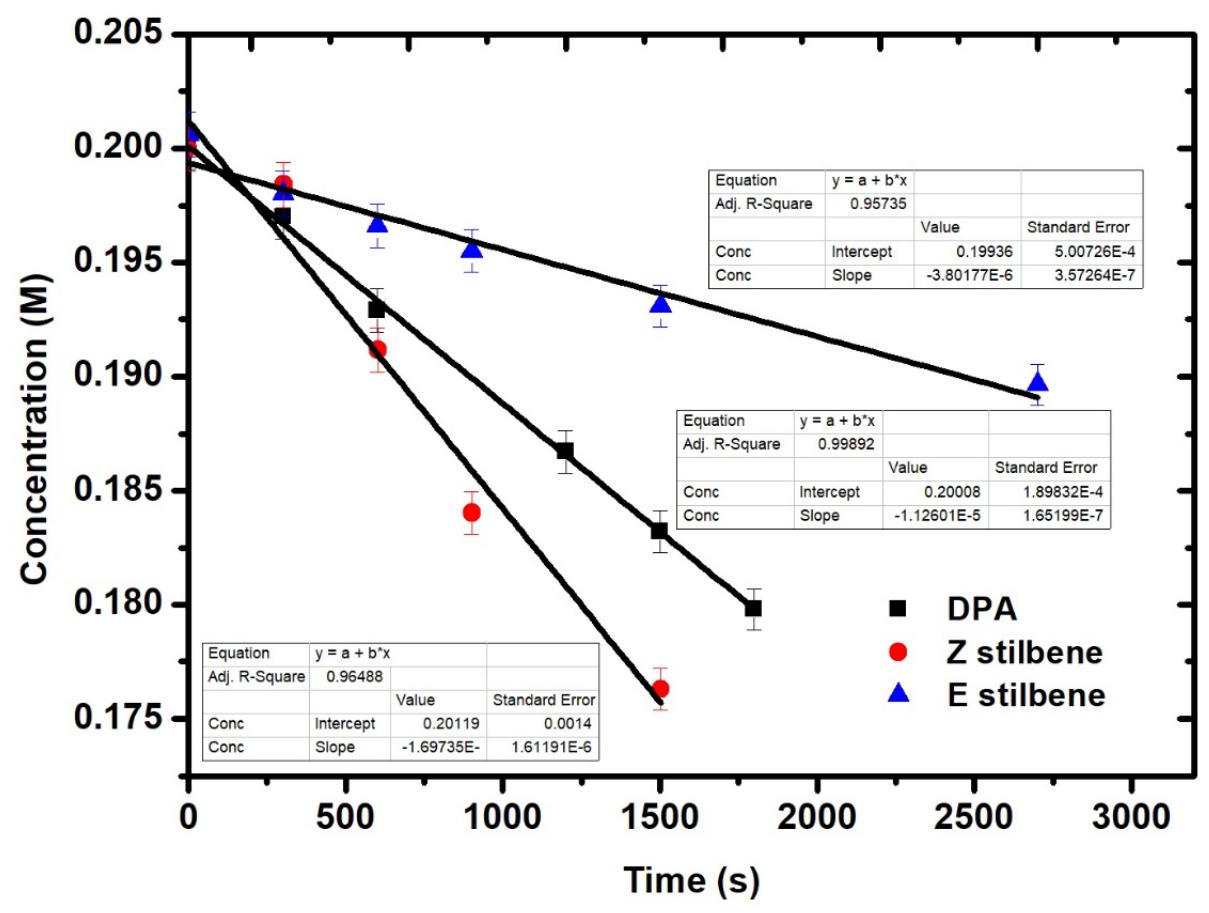

Figure S1. Plot of substrate concentration (M) versus time (s) for the catalyzed hydrogenation of DPA (black squares), $Z$-stilbene (red circles), and $E$-stilbene (blue triangles) under standard catalytic conditions. Each datum is the average of triplicate runs.

$\left[\mathrm{H}_{2}\right](\mathrm{mM})$

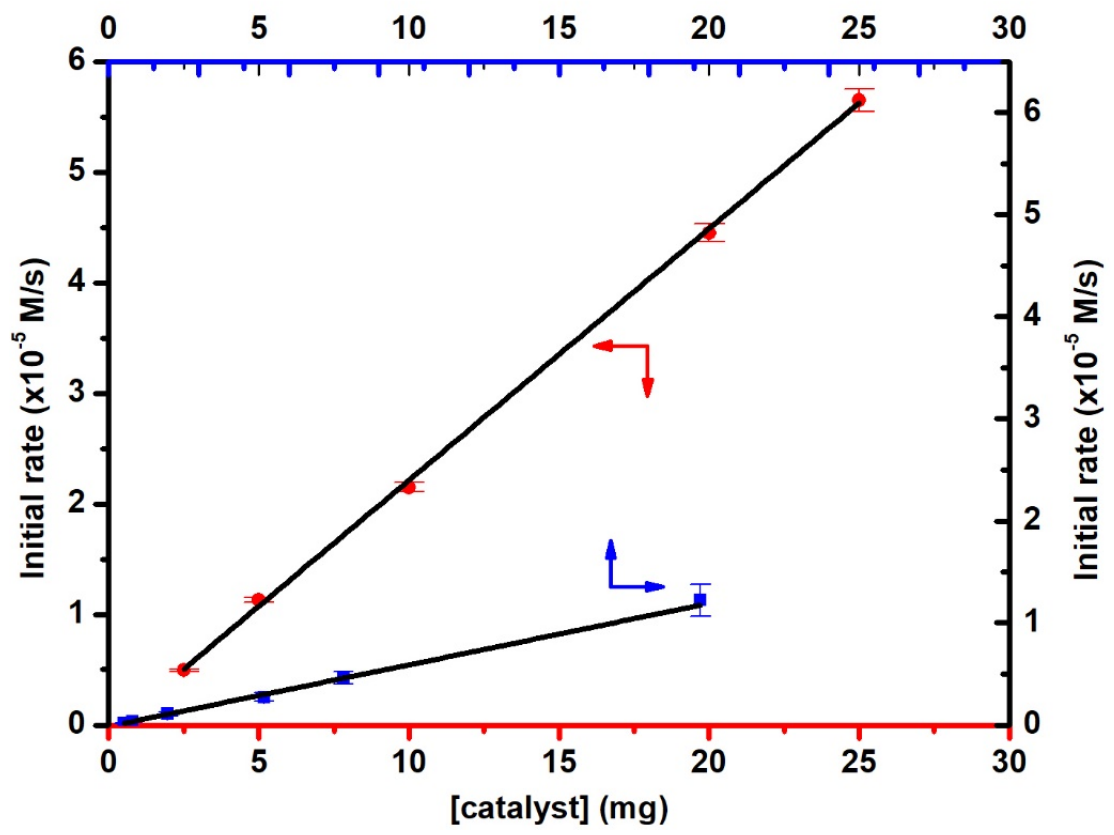

Figure S2. Plots of initial rate (M/s) of DPA hydrogenation versus catalyst $(\mathrm{mg})$ and $\left[\mathrm{H}_{2}\right]$ $(\mathrm{mM})$. See Experimental Section of main text for conditions. Each datum is the average of triplicate runs. 


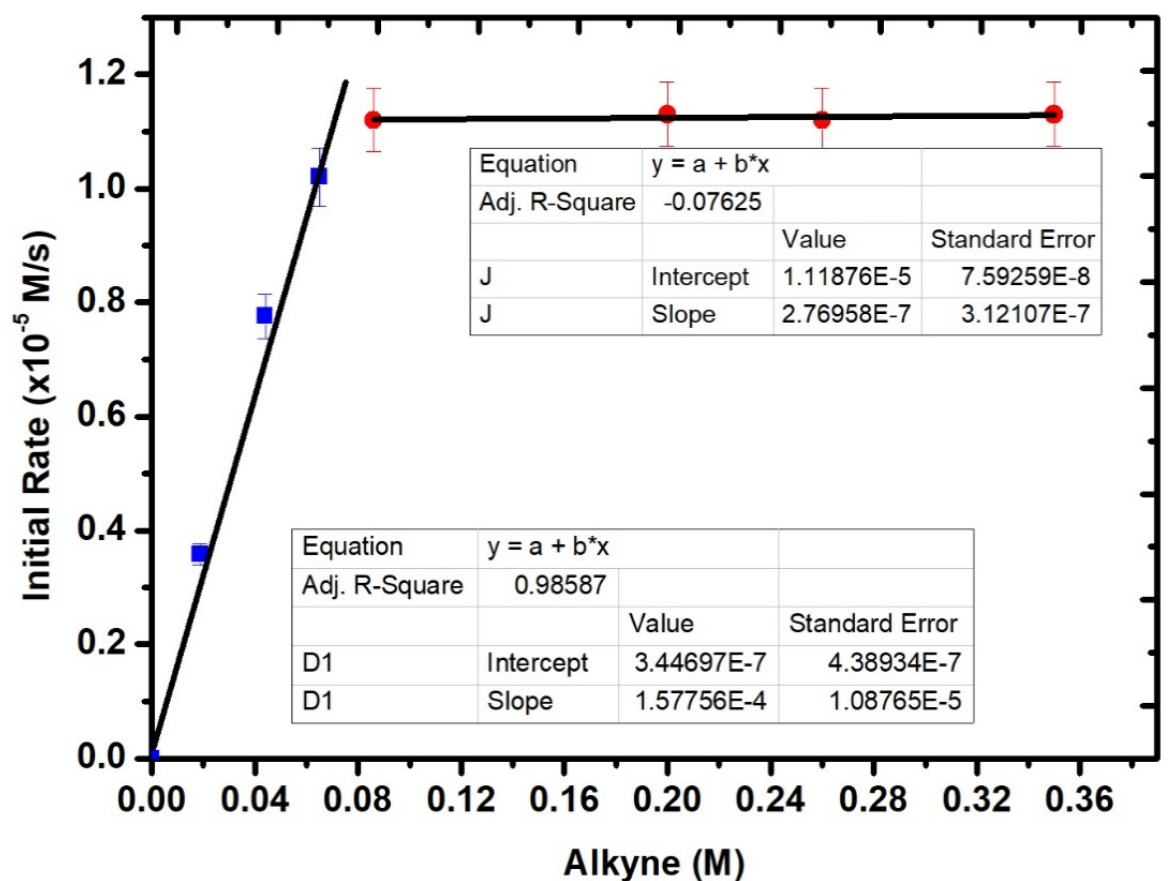

Figure S3. Plot of initial rate (M/s) versus DPA concentration (M) for catalytic hydrogenation. See Experimental Section of main text for conditions. Each datum is the average of triplicate runs.

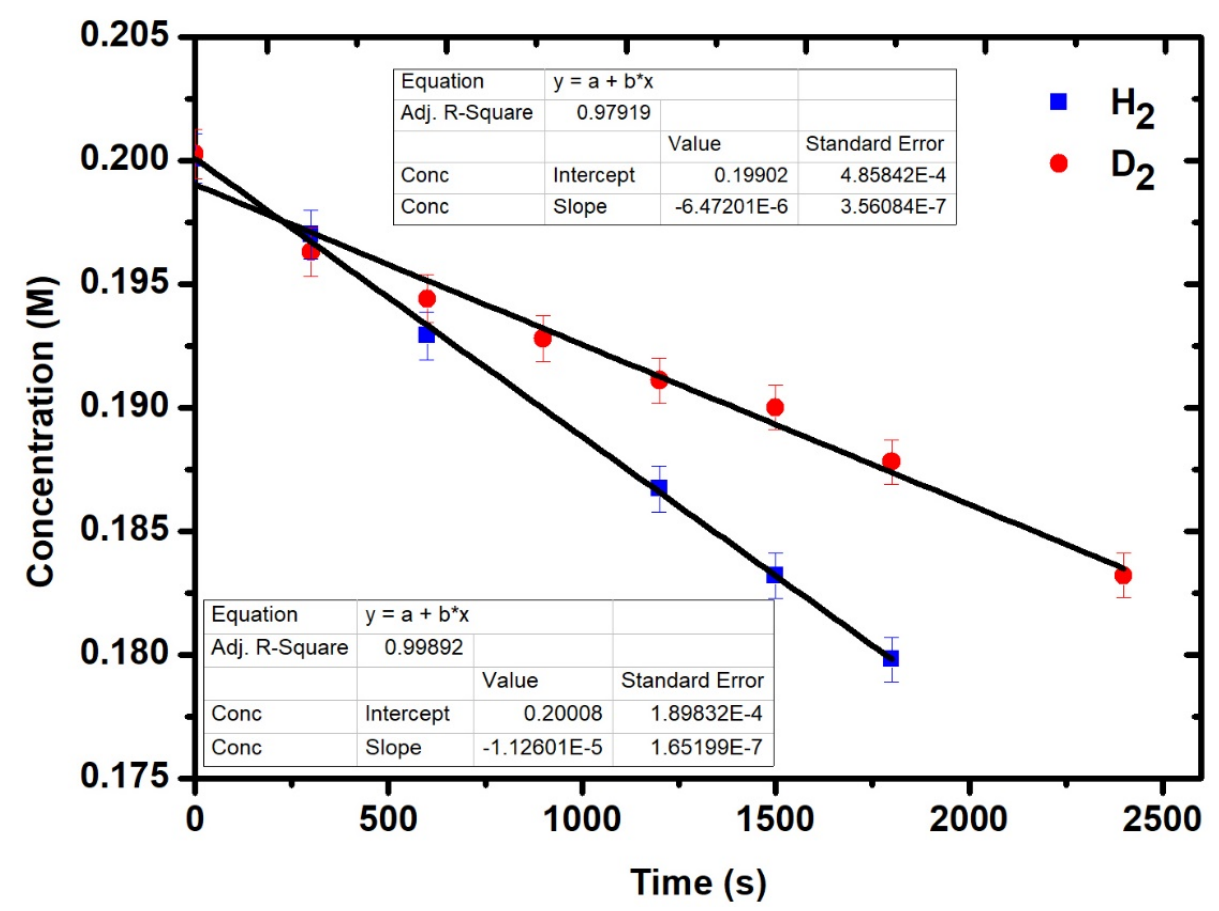

Figure S4. Plot of initial rate $(\mathrm{M} / \mathrm{s})$ versus DPA concentration $(\mathrm{M})$ for catalytic hydrogenation $\left(\mathrm{H}_{2}\right)$ versus deuteration $\left(\mathrm{D}_{2}\right)$ under standard catalytic conditions. The overall KIE was obtained by calculating the ratio of average initial rates (triplicate), rate $\mathrm{H}_{2} / \mathrm{rate}_{\mathrm{D} 2}$. 


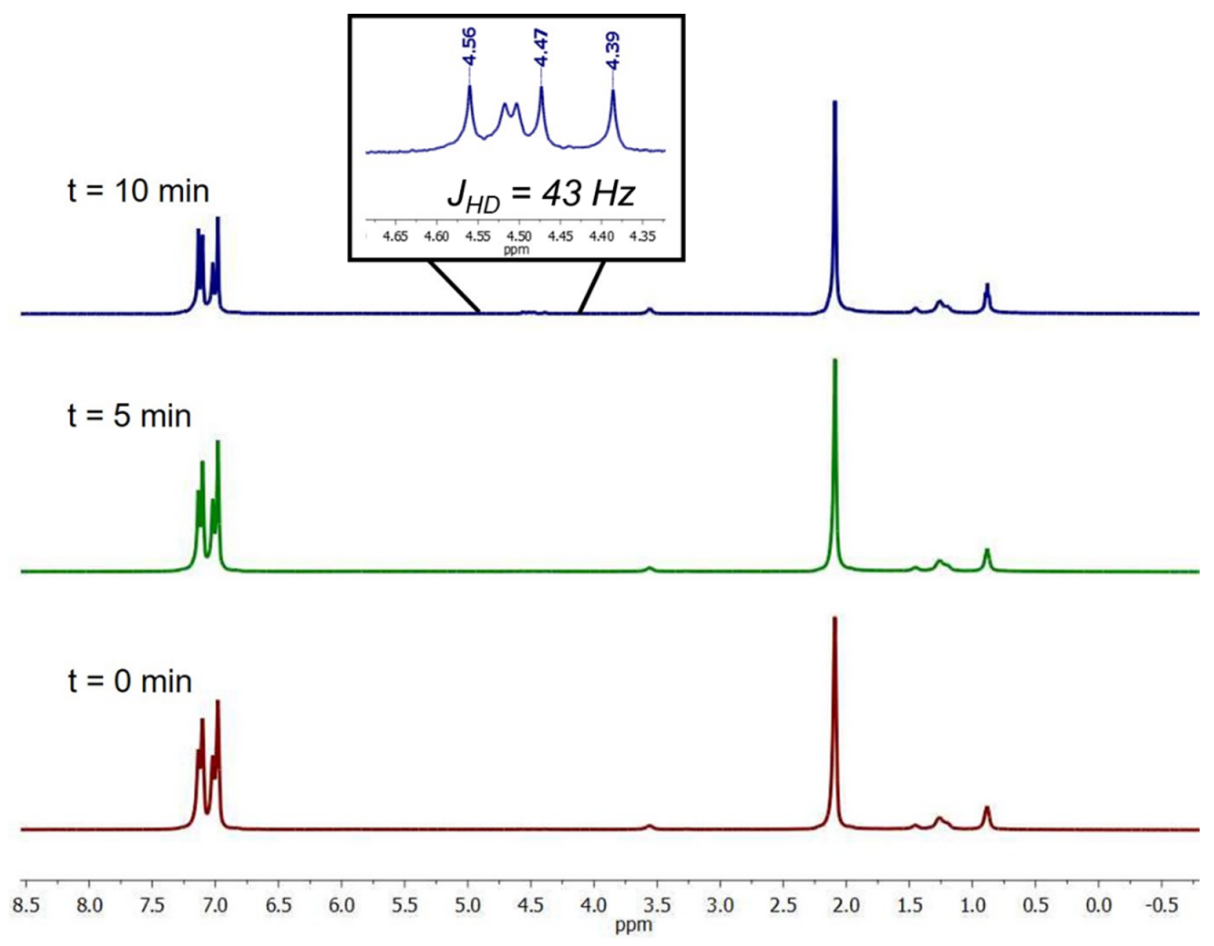

Figure S5. ${ }^{1} \mathrm{H}$ NMR spectrum (toluene-d8, $500 \mathrm{MHz}$ ) of the reaction between $\mathrm{Rh}-\mathrm{Ga} / \mathrm{NU}-1000$ and an equimolar mixture of $\mathrm{H}_{2} / \mathrm{D}_{2}$ at $\mathrm{rt}$. Significant formation of $\mathrm{HD}$ was observed after $\sim 10$ min at $100{ }^{\circ} \mathrm{C}$. The poorly resolved peak at $4.50 \mathrm{ppm}$ corresponds to $\mathrm{H}_{2}$ and is a consequence of poor shimming of the NMR sample containing solid MOF material.

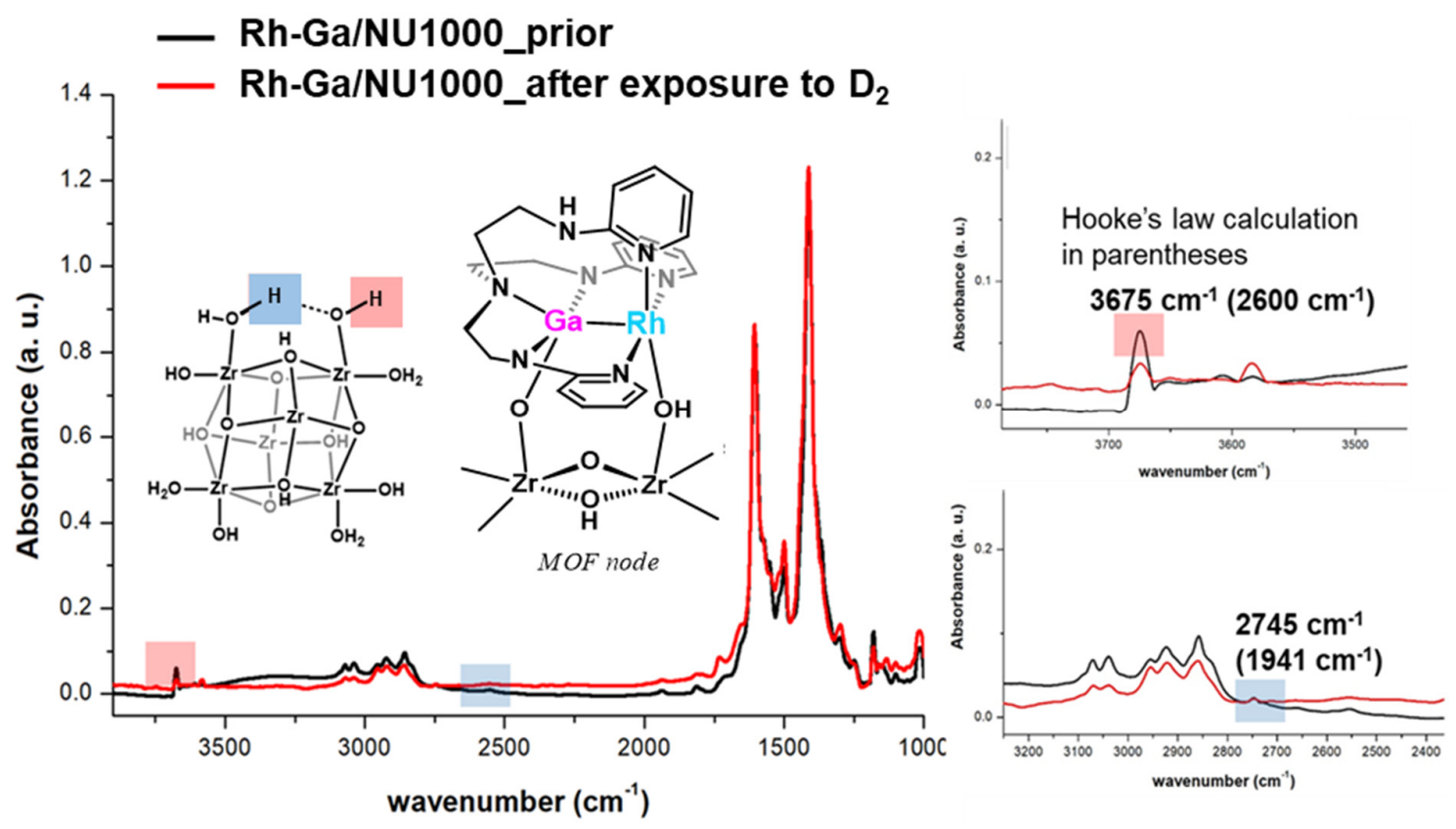

Figure S6. DRIFTS spectrum of Rh-Ga/NU-1000 before and after exposure to $\mathrm{D}_{2}(5 \mathrm{~atm})$ at $100{ }^{\circ} \mathrm{C}$ for $15 \mathrm{~h}$ suggesting that deuterium doesn't scramble with the protons from the MOF. The spectra were collected under an $\mathrm{N}_{2}$ atmosphere. Non-involvement of MOF protons was also confirmed by NMR spectroscopy; exposure of Rh-Ga/NU-1000 to $\mathrm{D}_{2}(5 \mathrm{~atm})$ at $100{ }^{\circ} \mathrm{C}$ for 15 h showed no $\mathrm{HD}$ or $\mathrm{H}_{2}$. 


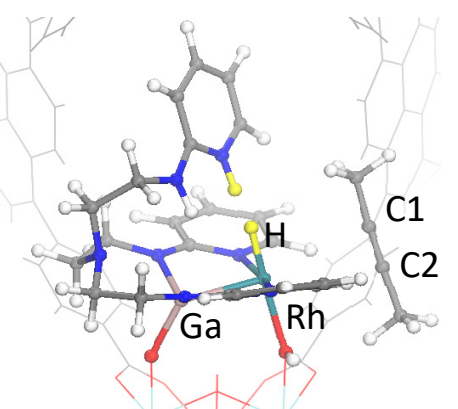

A

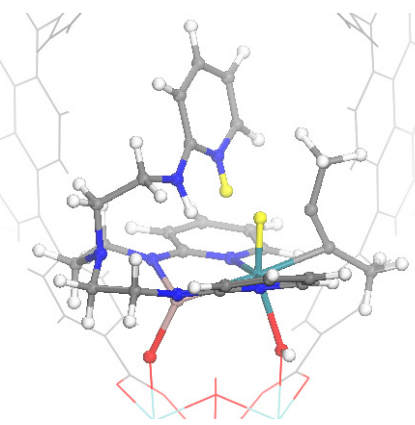

$\mathrm{TS}_{\mathrm{A}-\mathrm{B}}$

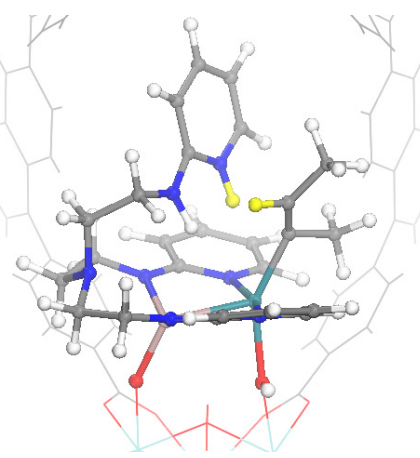

B

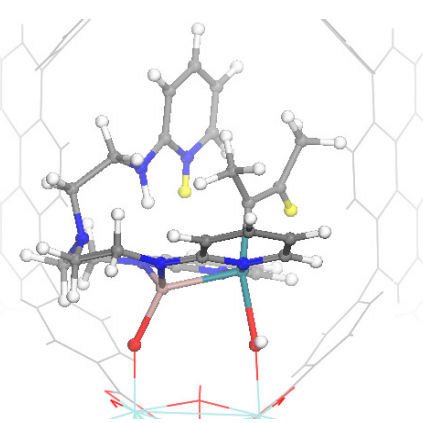

$B^{\prime}$

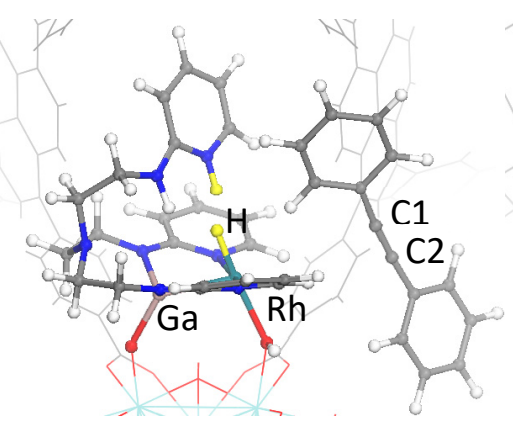

C

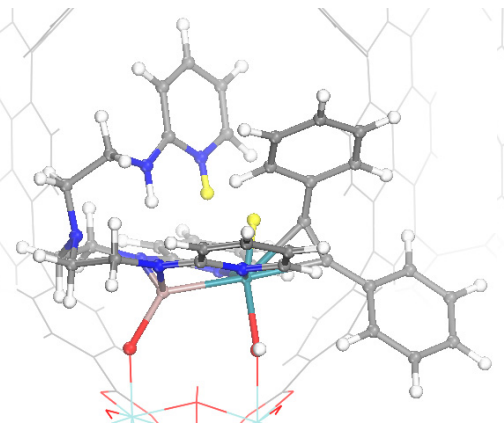

$\mathrm{TS}_{\mathrm{C}-\mathrm{D}}$

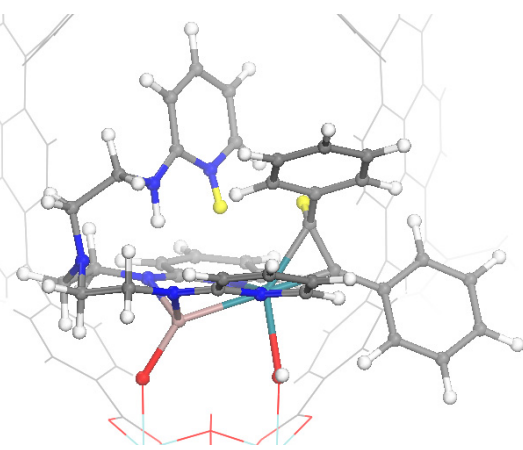

D

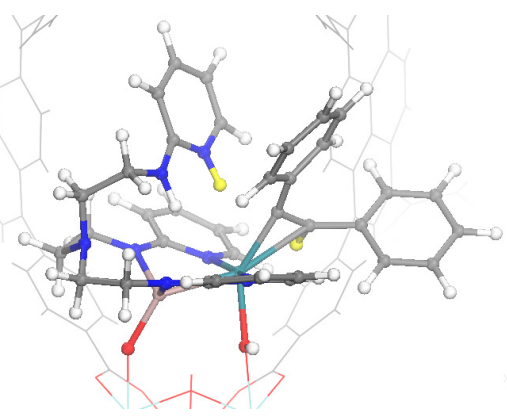

$D^{\prime}$

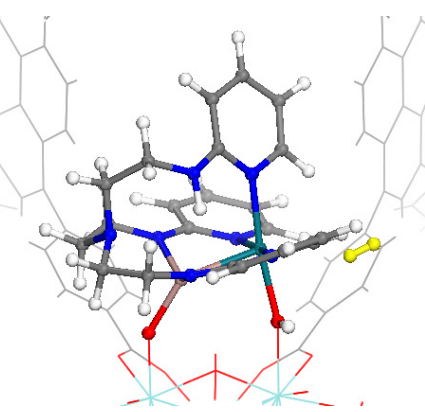

$\mathrm{E}$

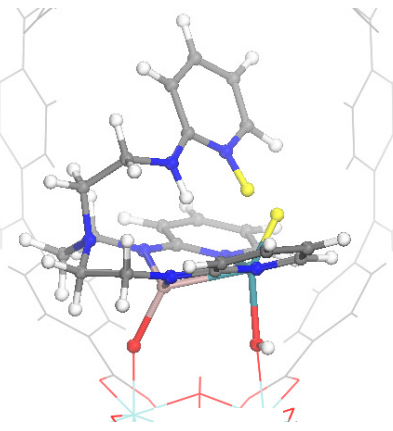

$\mathrm{TS}_{\mathrm{E}-\mathrm{F}}$

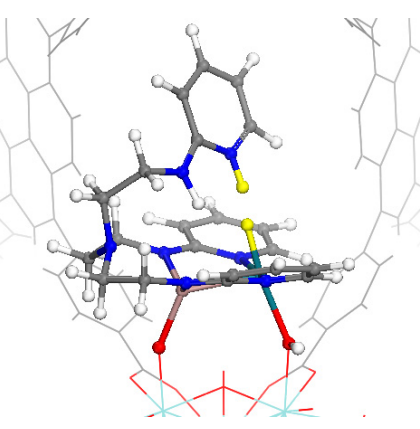

$\mathrm{F}$

Figure S7. The initial, transition and final structures (IS, TS, and FS) for 2-butyne insertion (A, TS $\left.\mathrm{A}_{\mathrm{B}} \mathrm{B}, \mathrm{B}\right)$, diphenylacetylene insertion $(\mathrm{C}, \mathrm{TS} \mathrm{C}-\mathrm{D}, \mathrm{D})$ and $\mathrm{H}_{2}$ heterolysis $\left(\mathrm{E}, \mathrm{TS}_{\mathrm{E}-\mathrm{F}}, \mathrm{F}\right)$. B' and $\mathrm{D}^{\prime}$, which are the isomers of $\mathrm{B}$ and $\mathrm{D}$, respectively, are formed via rotation of the Rh$\mathrm{C}$ (vinyl) bond and are energetically more stable. 
Table S1. The atomic charge of selected atoms.

\begin{tabular}{lccccc}
\hline Atomic charge & $\mathbf{H}$ & $\mathbf{C 1}$ & $\mathbf{C 2}$ & $\mathbf{R h}$ & Ga \\
\hline A & -0.206 & -0.069 & -0.046 & 0.046 & 0.889 \\
\hline TS $_{A-B}$ & -0.007 & -0.022 & -0.025 & -0.044 & 0.779 \\
\hline B $^{\prime}$ & 0.061 & -0.101 & -0.138 & 0.085 & 0.894 \\
\hline C & -0.220 & -0.111 & -0.111 & 0.046 & 0.894 \\
\hline TSC-D & -0.019 & -0.089 & -0.116 & 0.012 & 0.808 \\
\hline D' & 0.084 & -0.211 & -0.188 & 0.064 & 0.912 \\
\hline
\end{tabular}

Table S2. The enthalpy of activation $\left.\left(\Delta H_{0}\right)^{\ddagger}\right)$ and reaction $\left(\Delta H_{0}\right)$ at $0 \mathrm{~K}$ for $\mathrm{H}$ insertion to alkyne.

\begin{tabular}{llll}
\hline Alkyne insertion & $\Delta H_{0}^{\ddagger}$ & $\Delta H_{0}$ & $\Delta H_{0}$ \\
\hline 2-butyne & 19.7 & $-11.6(\mathrm{~A} \rightarrow \mathrm{B})$ & $-16.4\left(\mathrm{~A} \rightarrow \mathrm{B}^{\prime}\right)$ \\
\hline Diphenylacetylene & 22.3 & $19.0(\mathrm{C} \rightarrow \mathrm{D})$ & $-1.4\left(\mathrm{C} \rightarrow \mathrm{D}^{\prime}\right)$ \\
\hline
\end{tabular}

The kinetic isotope effect can be approximated as the ratio of the rates of reaction associated with $\mathrm{H}_{2}$ and $\mathrm{D}_{2}$, as show in eq (1)

$$
K I E=\frac{k_{H}}{k_{D}}
$$

Where $k_{H}$ and $k_{D}$ are the rates associated with $\mathrm{H}_{2}$ and $\mathrm{D}_{2}$, which are defined as eq (2) and eq (3):

$$
\begin{aligned}
& k_{H}=A \exp \left(\frac{-\Delta G_{H}^{\neq}}{R T}\right) \\
& k_{D}=A \exp \left(\frac{-\Delta G_{D}^{\neq}}{R T}\right)
\end{aligned}
$$

The entropy change is small which is approximated to be 0 and $\Delta G^{\neq} \approx \Delta H^{\ddagger}=\Delta E^{\ddagger}+\Delta Z P E$. Therefore,

$$
K I E=\frac{k_{H}}{k_{D}}=\frac{\exp \left[-\left(\Delta E_{H}^{\neq}+\Delta Z P E_{H}\right) / R T\right]}{\exp \left[-\left(\Delta E_{D}^{\neq}+\Delta Z P E_{D}\right) / R T\right]}
$$

Due to the electronic structure of $\mathrm{H}$ and $\mathrm{D}$ are the same, $\Delta E_{H}^{\neq}=\Delta E_{D}^{\neq}$, therefore KIE can be derived as eq (5):

\begin{tabular}{|c|c|c|c|c|c|c|}
\hline & \multicolumn{3}{|c|}{ Alkyne insertion } & \multicolumn{3}{|c|}{$\mathrm{H}_{2}$ heterolysis } \\
\hline & \multicolumn{2}{|c|}{ ZPE (kcal/mol) } & \multirow{2}{*}{$\begin{array}{l}\Delta \mathrm{ZPE} \\
(\mathrm{kcal} / \mathrm{mol}) \\
\mathrm{A} \rightarrow \mathrm{TS}_{\mathrm{A}-\mathrm{B}}\end{array}$} & \multicolumn{2}{|c|}{ ZPE (kcal/mol) } & $\triangle \mathrm{ZPE}(\mathrm{kcal} / \mathrm{mol})$ \\
\hline & A & $\mathrm{TS}_{\mathrm{A}-\mathrm{B}}$ & & $\mathrm{E}$ & TSE-F & $\mathrm{E} \rightarrow \mathrm{TS} \mathrm{S}-\mathrm{F}$ \\
\hline H & 357.919 & 355.234 & -2.595 & 300.949 & 300.515 & -0.434 \\
\hline D & 354.380 & 352.078 & -2.302 & 298.639 & 297.933 & -0.706 \\
\hline KIE & & & 1.642 & & & 0.632 \\
\hline
\end{tabular}

$$
K I E=\exp \frac{-\left(\triangle Z P E_{H}-\triangle Z P E_{D}\right)}{R T}
$$

Table S3. Zero point energy of A, TS A-B, C and TSC-D. 


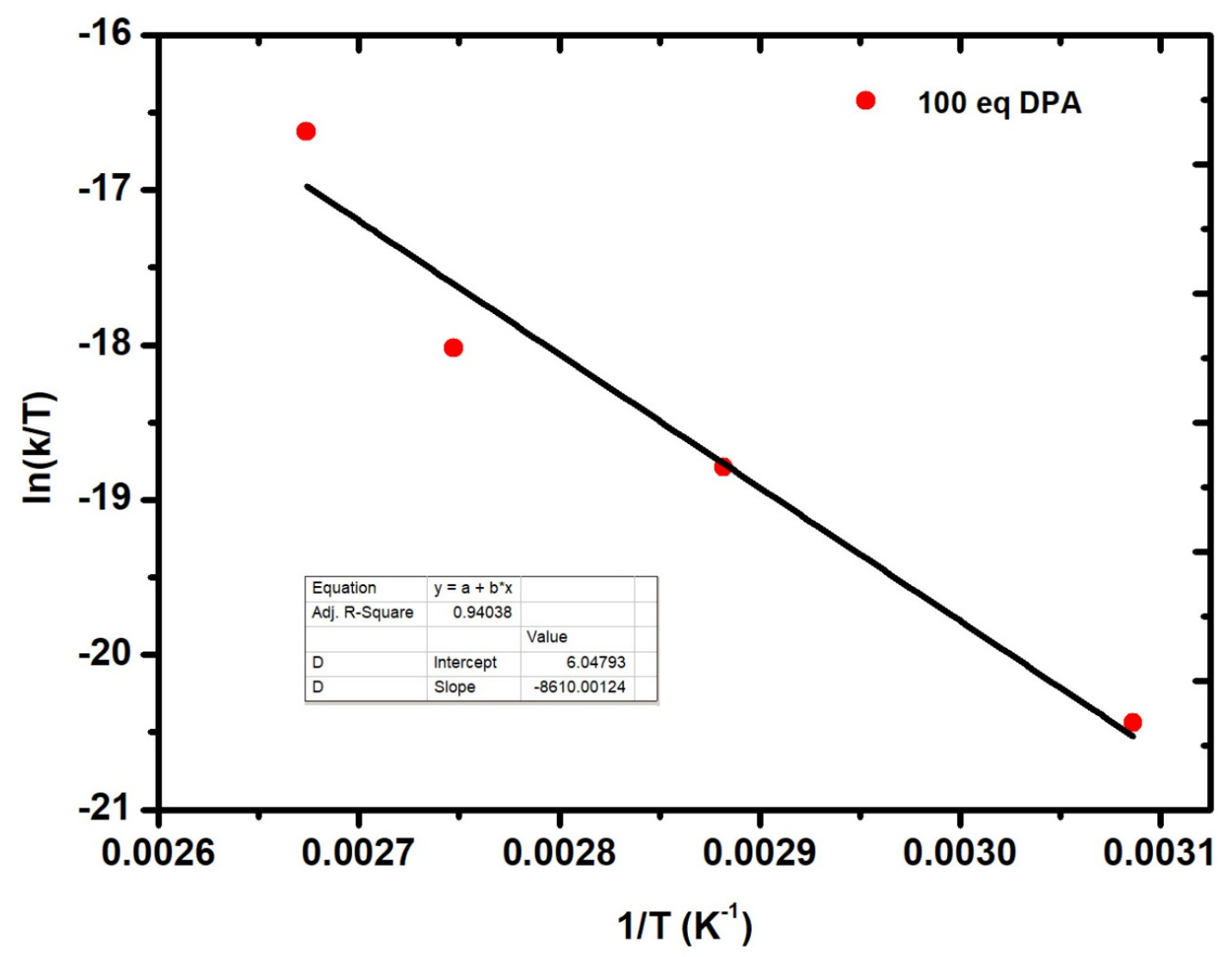

Figure S8. The impact of temperature on the rate was studied in the range $50-100{ }^{\circ} \mathrm{C}$, at a catalyst loading of $1 \mathrm{~mol} \%(0.002 \mathrm{mM})$, dihydrogen pressure of $5 \mathrm{~atm}$ and a diphenylacetylene concentration of $0.21 \mathrm{mM}$ in d8-toluene. $10 \mathrm{mg}$ of $1,3,5$ trimethoxybenzene was used an internal standard. An Eyring plot constructed from the kinetic data obtained furnished the following activation parameters: $\Delta H^{t}=17 \mathrm{kcal} / \mathrm{mol}$ and $\Delta S^{t}=-35 \mathrm{cal} \mathrm{mol}^{-1} \mathrm{~K}^{-1}$. The large negative value for the entropy of activation is consistent with an associative mechanism and also suggestive of a highly ordered metallacycle transition state. 


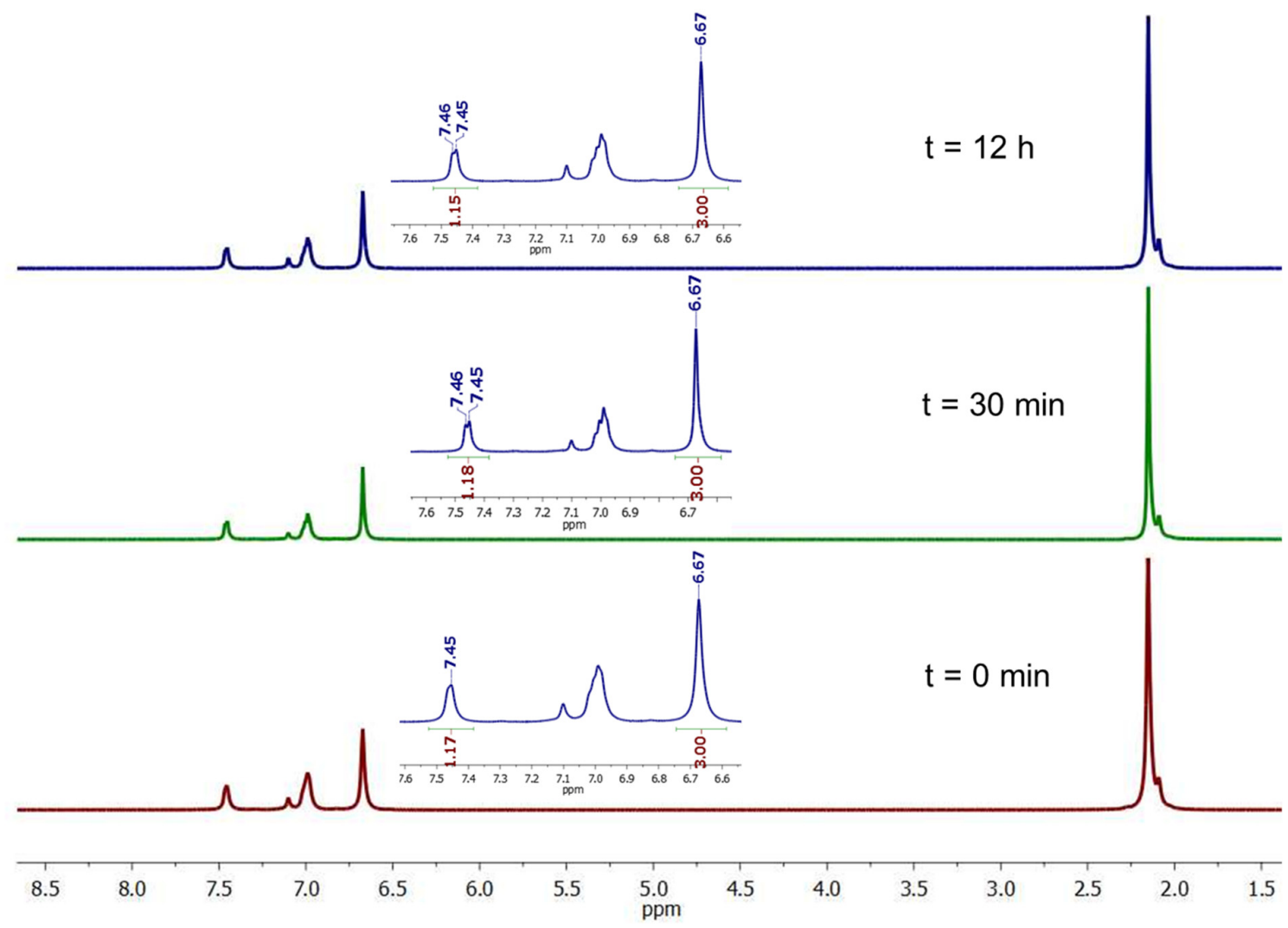

Figure S9. ${ }^{1} \mathrm{H}$ NMR spectrum (toluene- $\mathrm{d}_{8}, 500 \mathrm{MHz}$ ) of the reaction between diphenylacetylene (10 eq., $6.5 \mathrm{mg}, 36.7 \mu \mathrm{mol})$ and $\mathrm{Rh}-\mathrm{Ga} / \mathrm{NU}-1000(10 \mathrm{mg}, 3.67 \mu \mathrm{mol})$ in the presence of mesitylene $(10 \mu \mathrm{L}$, internal standard $)$ at $100{ }^{\circ} \mathrm{C}$. The amount of alkyne in solution $(7.45 \mathrm{ppm})$ remains unchanged relative to the internal standard $(6.67 \mathrm{ppm})$. 


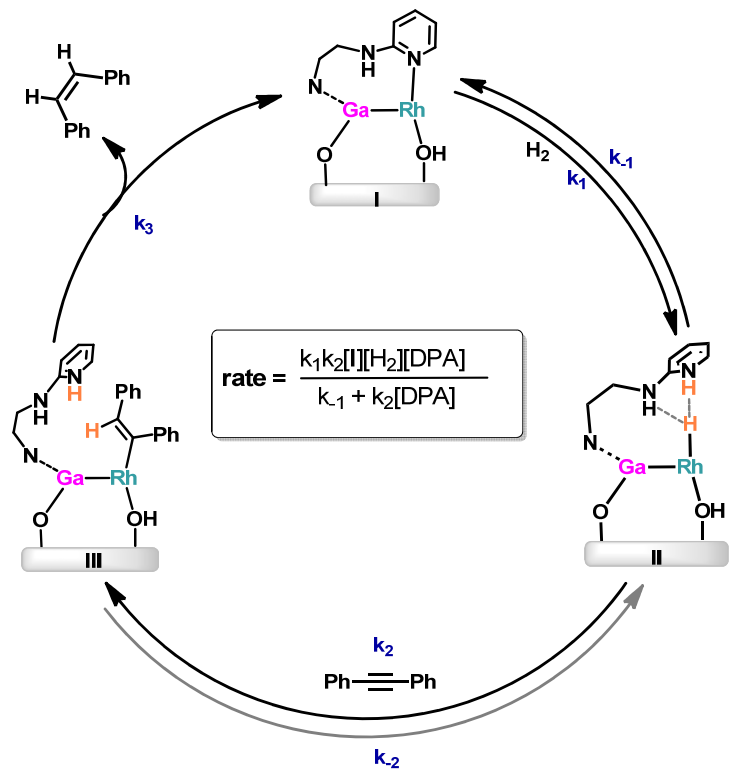

$$
\begin{aligned}
& \text { Derivation of rate law } \\
& \text { rate }=\frac{\mathrm{d}[\text { alkene }]}{\mathrm{dt}}=\mathrm{k}_{3}[\mathrm{III}] \\
& \text { Using steady state approximation, } \frac{\mathrm{d}[\mathrm{III}]}{\mathrm{dt}}=\frac{\mathrm{d}[\mathrm{II}]}{\mathrm{dt}}=0 \\
& \mathrm{k}_{3}[\mathrm{III}]+\mathrm{k}_{2}[\mathrm{III}]-\mathrm{k}_{2}[\mathrm{DPA}][\mathrm{II}]=0 \text { or }[\mathrm{III}]_{\mathrm{ss}}=\frac{\mathrm{k}_{2}[\mathrm{DPA}][\mathrm{II}]}{\mathrm{k}_{3}+\mathrm{k}_{-2}} \\
& \text { Similarly, }[\mathrm{II}]_{\mathrm{ss}}=\frac{\mathrm{k}_{2}[\mathrm{III}]+\mathrm{k}_{1}\left[\mathrm{H}_{2}[\mathrm{Il}]\right.}{\mathrm{k}_{-1}+\mathrm{k}_{2}[\mathrm{DPA}]} \\
& \text { From DFT, } \mathrm{k}_{-2} \sim 0 \\
& {[I I]_{\mathrm{ss}}=\frac{\mathrm{k}_{1}\left[\mathrm{H}_{2}\right][\mathrm{l}]}{\mathrm{k}_{-1}+\mathrm{k}_{2}[\mathrm{DPA}]} \text { and }[\mathrm{III}]_{\mathrm{ss}}=\frac{\mathrm{k}_{2}[\mathrm{DPA}][\mathrm{II}]}{\mathrm{k}_{3}}} \\
& \frac{\mathrm{d}[\text { alkene }]}{\mathrm{dt}}=\frac{\mathrm{k}_{1} \mathrm{k}_{2}[\mathrm{l}]\left[\mathrm{H}_{2}\right][\mathrm{DPA}]}{\mathrm{k}_{-1}+\mathrm{k}_{2}[\mathrm{DPA}]} \\
& \text { At high alkyne concentrations } \\
& \text { rate }=\frac{\mathrm{d}[\mathrm{alkene}]}{\mathrm{dt}}=\mathrm{k}_{1}[\mathrm{l}]\left[\mathrm{H}_{2}\right]
\end{aligned}
$$

Figure S10. Simplified mechanism for DPA semihydrogenation and derivation of the corresponding rate law. Assumptions: Steps III $\rightarrow$ I and III $\rightarrow$ II are irreversible. Intermediates II and III follow steady-state kinetics.

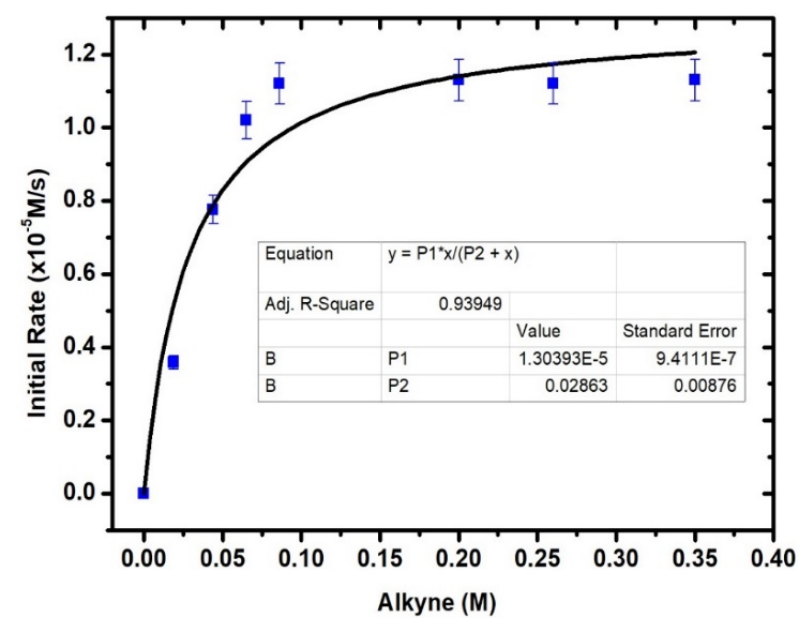

$$
\begin{aligned}
& \frac{\mathrm{d}[\text { alkene }]}{\mathrm{dt}}=\frac{\mathrm{k}_{1} \mathrm{k}_{2}[\mathrm{l}]\left[\mathrm{H}_{2}\right][\mathrm{DPA}]}{\mathrm{k}_{1}+\mathrm{k}_{2}[\mathrm{DPA}]} \\
& \frac{\mathrm{d}[\text { alkene }]}{\mathrm{dt}}=\frac{\left.\mathrm{P}_{1} \text { [alkyne }\right]}{\left.\mathrm{P}_{2}+\text { [alkyne }\right]} \quad \text { (where } P_{1}=k_{1} \text { and } P_{2}=k_{-1} / k_{2} \text { ) } \\
& \mathrm{P}_{1}=1.3 \times 10^{-5} \mathrm{~s}^{-1} \text { and } \mathrm{P}_{2}=0.028 \mathrm{M} \\
& \mathrm{k}_{1}=1.3 \times 10^{-5} \mathrm{~s}^{-1} \text { and } \mathrm{k}_{-1} / \mathrm{k}_{2}=0.028 \mathrm{M}
\end{aligned}
$$

Figure S11. Plot of initial rate $(\mathrm{M} / \mathrm{s})$ versus DPA concentration $(\mathrm{M})$, shown with a simulation of the rate equation (derived above). The fit of the constants, $\mathrm{P}_{1}$ and $\mathrm{P}_{2}$, has a $\mathrm{R}^{2}$ value of 0.94 . 

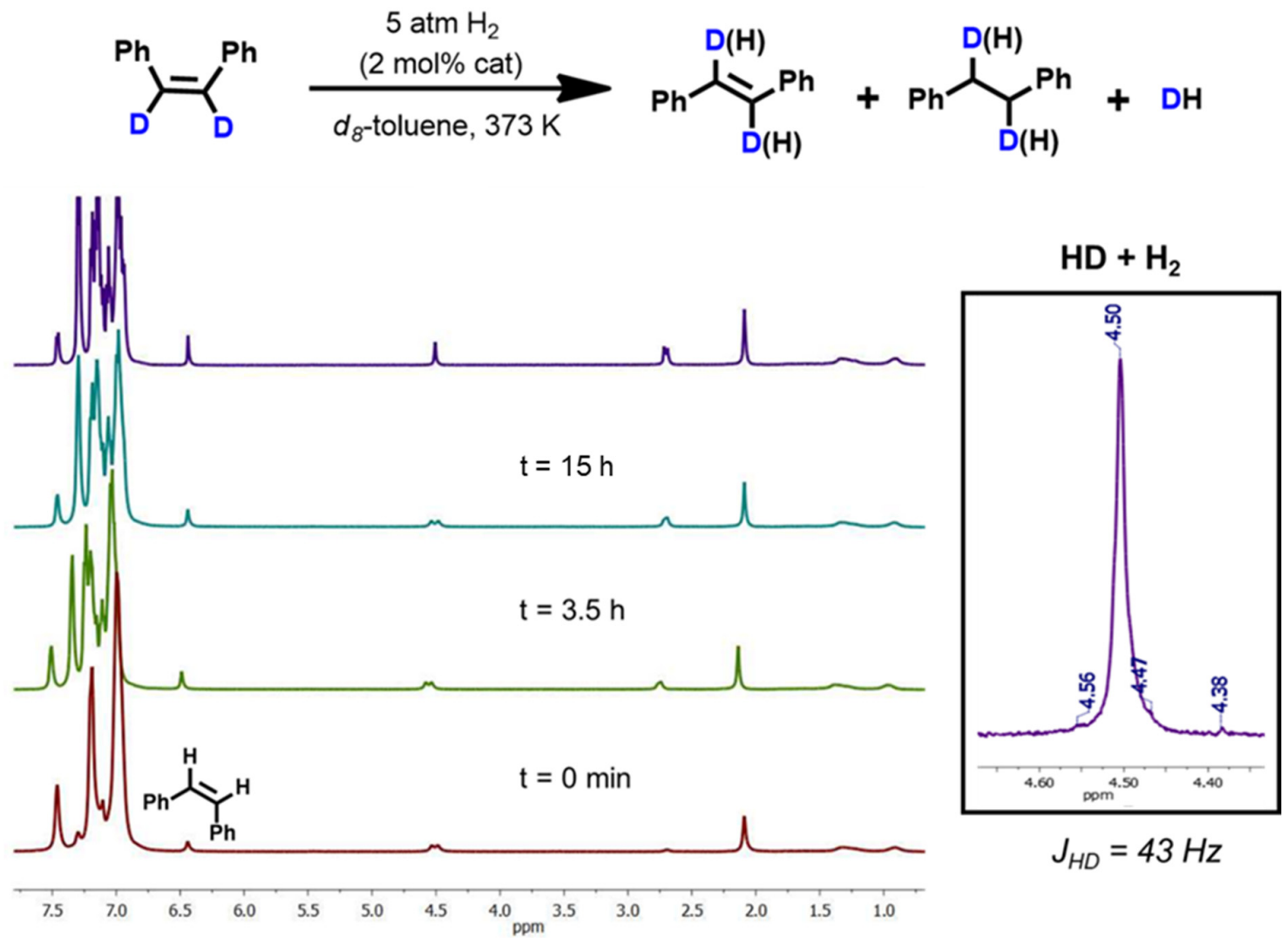

Figure S12. ${ }^{1} \mathrm{H}$ NMR spectrum (toluene-d8, $500 \mathrm{MHz}$ ) spectrum of the reaction between $Z$ stilbene- $d_{2}$ and $\mathrm{H}_{2}$ under standard catalytic conditions. The final (top) spectrum was collected after cooling down the J. Young NMR tube to $-78^{\circ} \mathrm{C}$ to improve the solubility of HD in the solvent. The poorly resolved peak at $4.50 \mathrm{ppm}$ corresponds to $\mathrm{H}_{2}$ and is a consequence of poor shimming of the NMR sample in the presence of solid MOF material.

${ }^{2} \mathrm{H}$ NMR (THF)

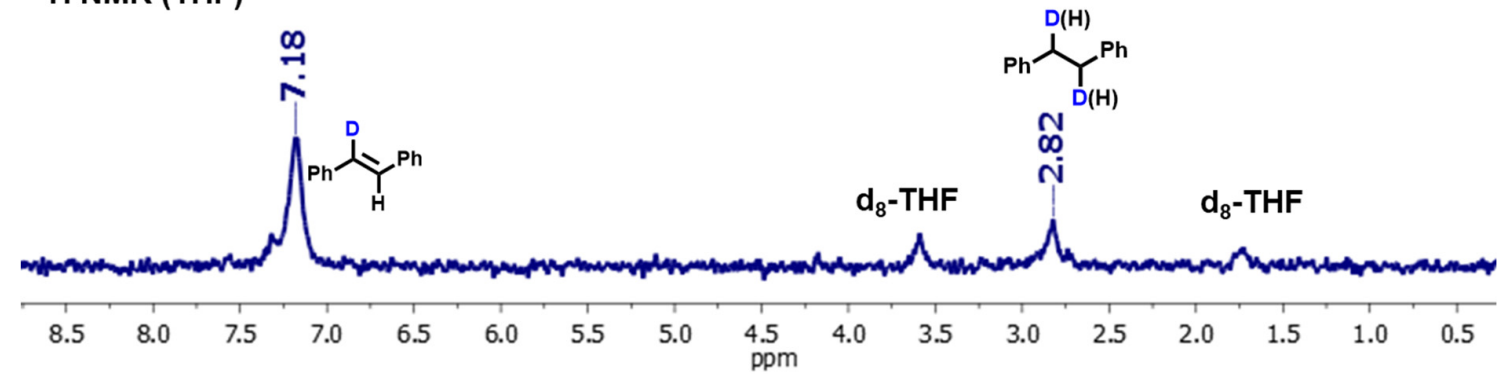

Figure S13. ${ }^{2} \mathrm{H}$ NMR spectrum (hexane, $61.4 \mathrm{MHz}$ ) of the product mixture from the above experiment showing deuterated $E$-stilbene and bibenzyl. 

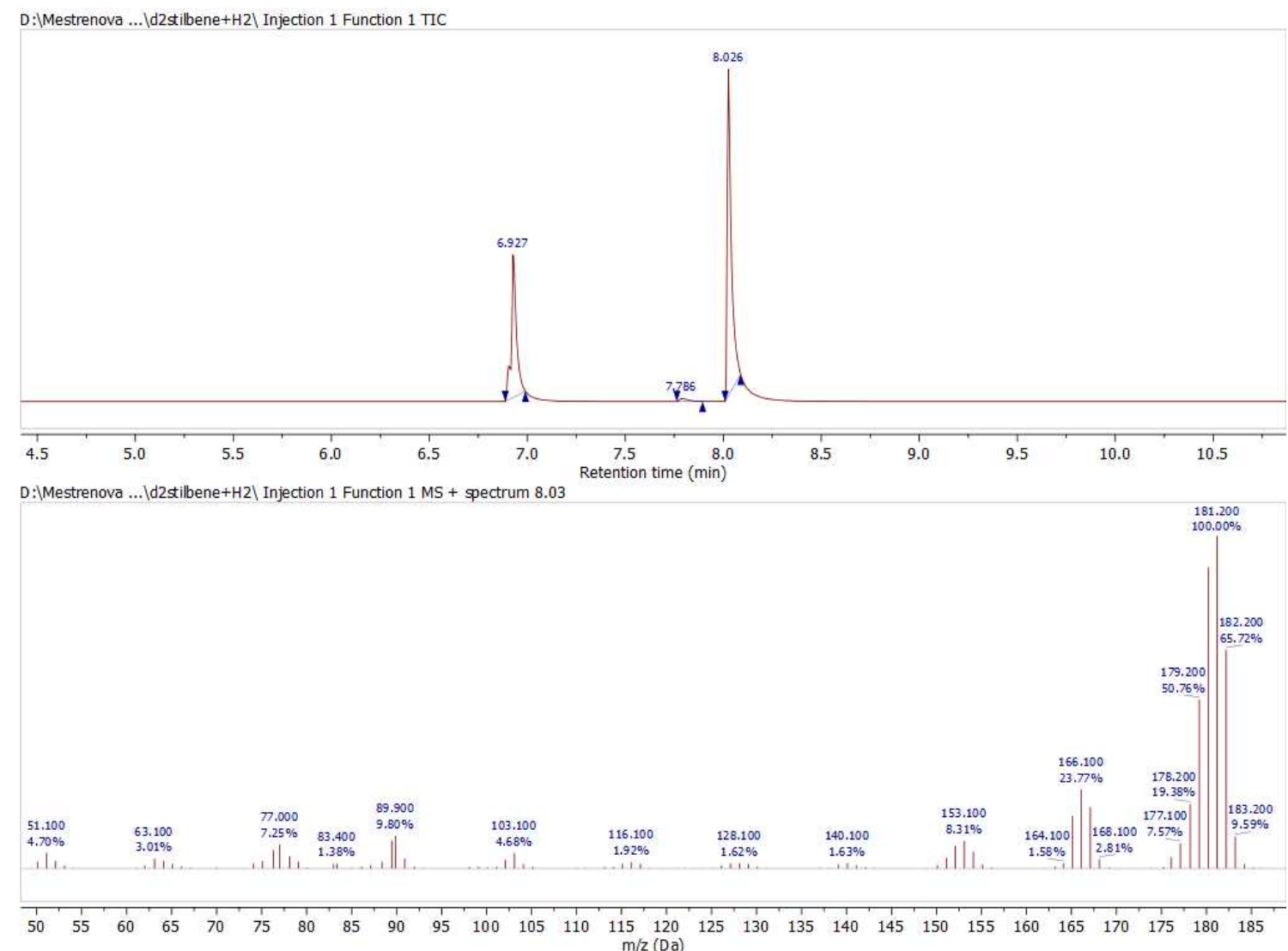

Figure S14. Analysis of products by GC-MS from the reaction between $Z$-stilbene- $d_{2}$ and $\mathrm{H}_{2}$ under standard catalytic conditions. The peak at $8.03 \mathrm{~min}$ corresponds to the alkene mixture as evidenced by the MS spectrum (bottom) wherein the major peak at $181.2(\mathrm{~m} / \mathrm{z}$ ) corresponds to monodeuterated stilbene $\left(\mathrm{C}_{14} \mathrm{H}_{11} \mathrm{D}\right)$ and the minor peak at $182.2(\mathrm{~m} / \mathrm{z})$ corresponds to the bisdeuterated stilbene $\left(\mathrm{C}_{14} \mathrm{H}_{10} \mathrm{D}_{2}\right)$. The peak at $6.93 \mathrm{~min}$ is a mixture of bibenzyl and toluene. 


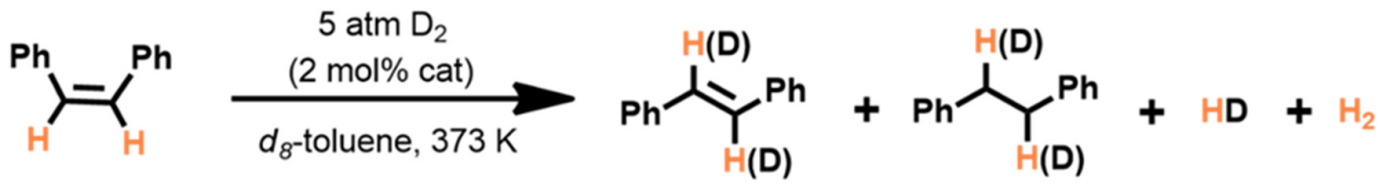

${ }^{1} \mathrm{H}$ NMR

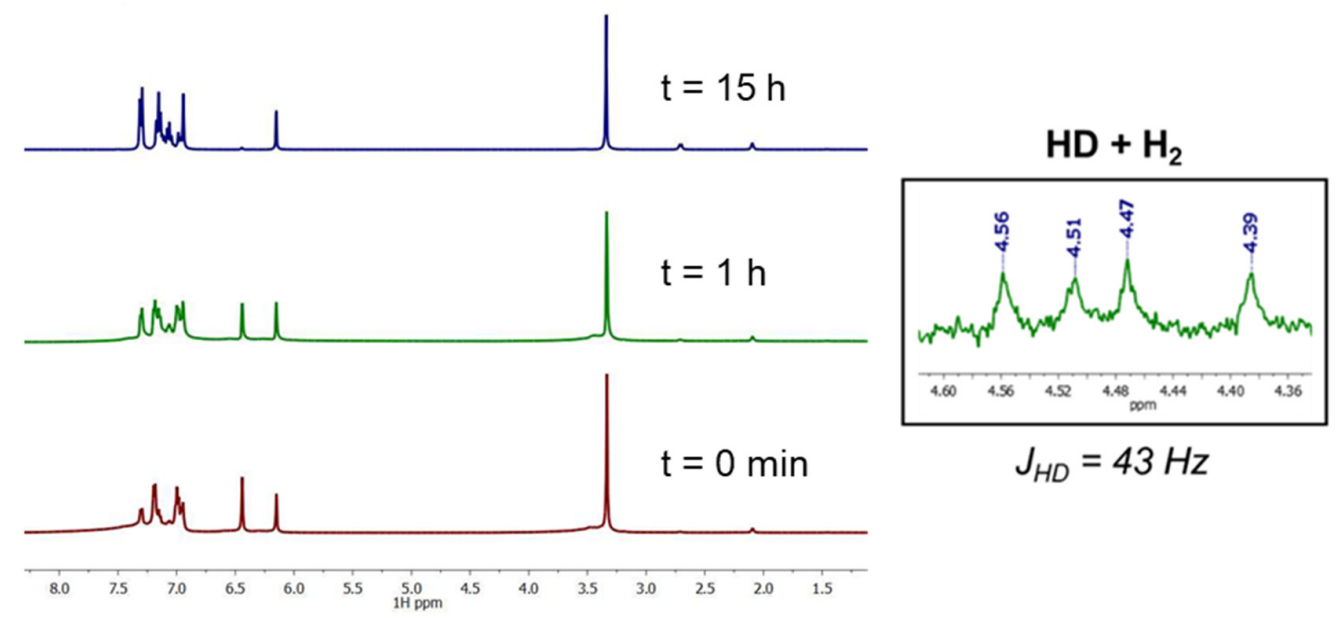

Figure S15. ${ }^{1} \mathrm{H}$ NMR spectrum (toluene-d8, $500 \mathrm{MHz}$ ) spectrum of the reaction between $Z$ stilbene and $\mathrm{D}_{2}$ under standard catalytic conditions with $10 \mathrm{mg}$ of 1,3,5-trimethoxybenzene as the internal standard. Trans-stilbene was obtained in $88 \%$ yield as the major product with $\mathrm{D}_{2}$ (see below). Minor amounts of trans-stilbene- $d_{1}(7 \%)$, bibenzyl- $d_{1-2}(\sim 4$ to $7 \%), \mathrm{HD}$ and $\mathrm{H}_{2}$ (inset) were also observed.

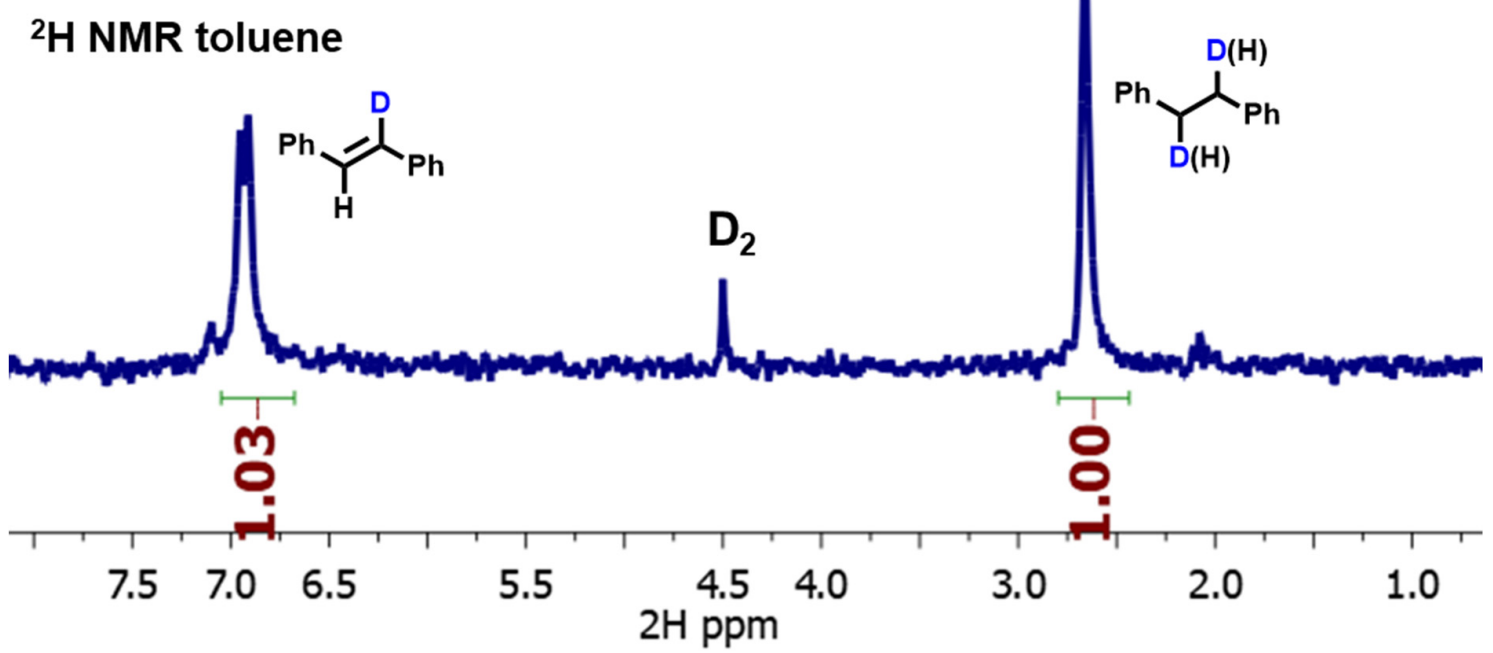

Figure S16. ${ }^{2} \mathrm{H}$ NMR spectrum (toluene, $61.4 \mathrm{MHz}$ ) spectrum of the reaction between $Z$ stilbene and $\mathrm{D}_{2}$ under standard catalytic conditions with $10 \mathrm{mg}$ of 1,3,5-trimethoxybenzene as the internal standard. 

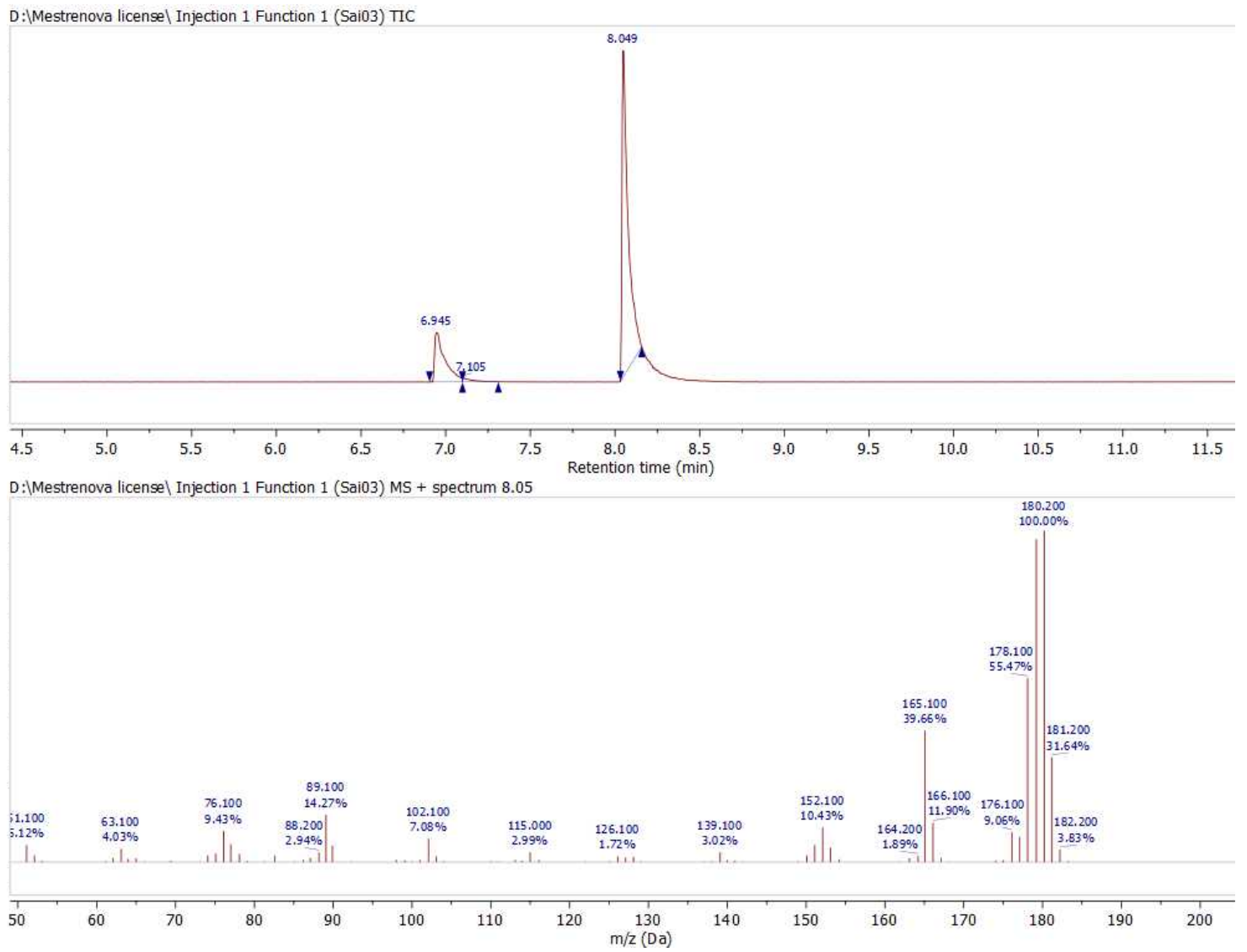

Figure S17. Analysis of products by GC-MS from the reaction between Z-stilbene and $\mathrm{D}_{2}$ under standard catalytic conditions. The peak at 8.05 min corresponds to the alkene mixture as evidenced by the MS spectrum (bottom) wherein the major peak at $180.2(\mathrm{~m} / \mathrm{z}$ ) corresponds to protio-stilbene $\left(\mathrm{C}_{14} \mathrm{H}_{12}\right) .{ }^{1}$ The peak at $6.94 \mathrm{~min}$ is a mixture of bibenzyl and toluene. 

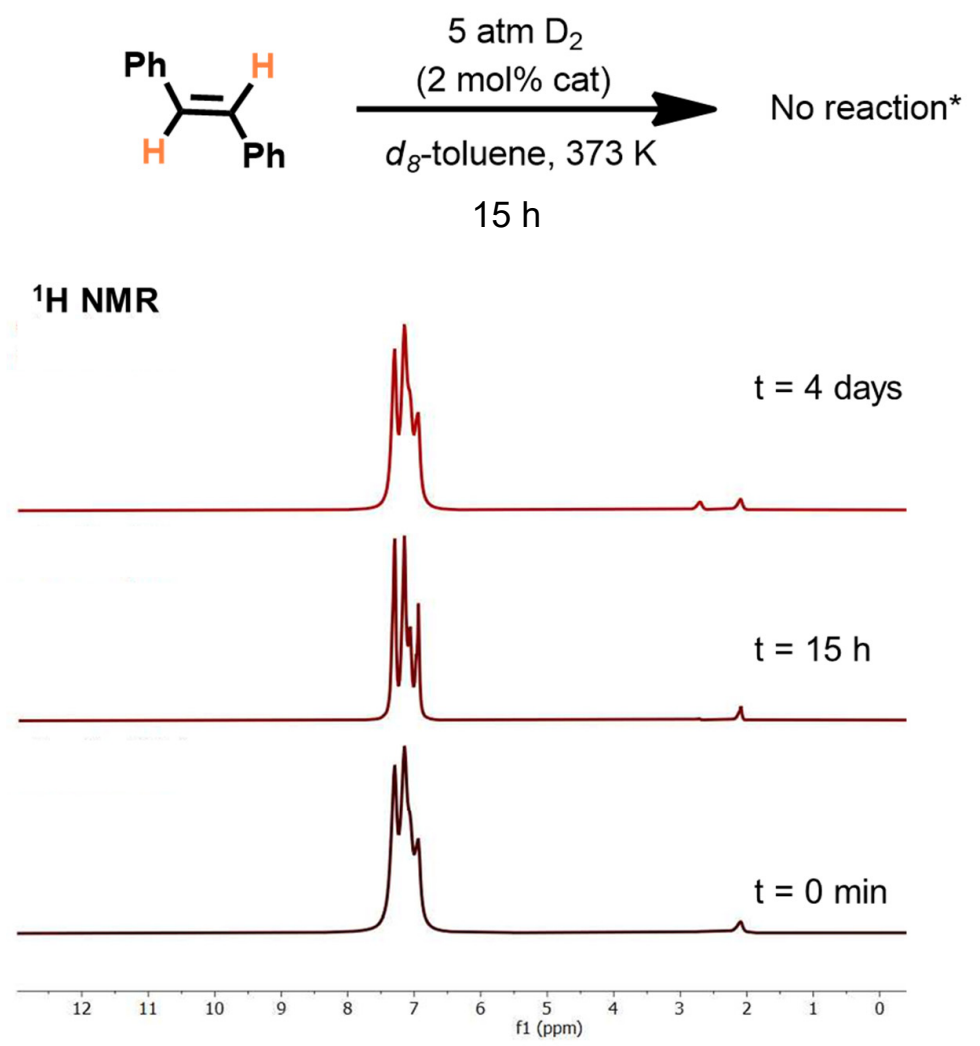

Figure S18. ${ }^{1} \mathrm{H}$ NMR spectrum (toluene-d8, $500 \mathrm{MHz}$ ) of spectrum of the reaction between $E$ stilbene and $\mathrm{D}_{2}$ under standard catalytic conditions. *No significant deuterium incorporation is observed during the standard catalytic time course $(15 \mathrm{~h})$; however, deuterium incorporation is observed after 4 days. Inset (right) shows the formation of $\mathrm{HD}$ and $\mathrm{H}_{2}$ after 4 days. 


\section{Synthesis and characterization of monosubstituted diphenylacetylenes and $Z$-stilbene-d 2}

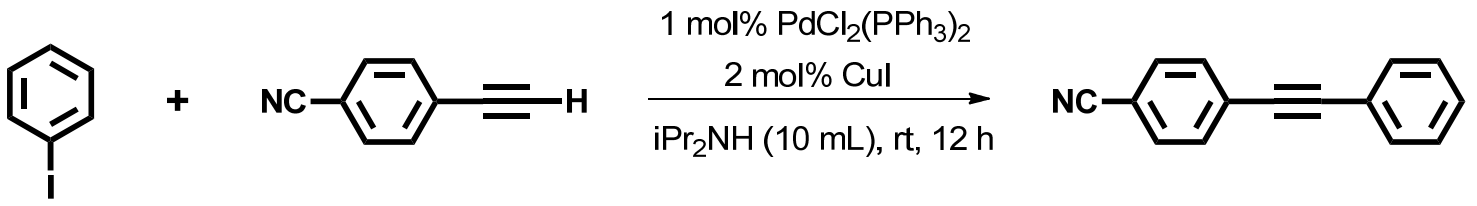

Adapting reported procedure ${ }^{2}$ : A $10 \mathrm{~mL} i \mathrm{Pr}_{2} \mathrm{NH}$ solution containing $\mathrm{PdCl}_{2}\left(\mathrm{PPh}_{3}\right)_{2}(27.6 \mathrm{mg}$, $0.0393 \mathrm{mmol}), \mathrm{CuI}(15 \mathrm{mg}, 0.0786 \mathrm{mmol})$ and iodobenzene $(802 \mathrm{mg}, 440 \mu \mathrm{L}, 3.93 \mathrm{mmol})$ was degassed using $\mathrm{N}_{2}$ for 20 minutes in a $50 \mathrm{~mL}$ Schlenk flask equipped with a stir bar. 4Ethynylbenzonitrile (500 $\mathrm{mg}, 3.93 \mathrm{mmol}$ ) was added to the reaction mixture in two portions over the course of 30 minutes and the contents of the flask were stirred under a steady stream of nitrogen for $12 \mathrm{~h}$. The reaction mixture was filtered through a plug of silica by washing with hexanes $(2 \times 50 \mathrm{~mL})$. The orange solution was then dried in vacuo and purified using column chromatography (2.5\% EtOAc in hexanes as the eluting mixture). Yield $=500 \mathrm{mg}(63 \%)$.

${ }^{1} \mathrm{H}$ NMR $\left(\mathrm{CDCl}_{3}, 500 \mathrm{MHz}\right)$ ppm: 7.67-7.57 (m, 4H), 7.57-7.52 (m, 2H), 7.41-7.34 (m, 3H). ${ }^{3}$
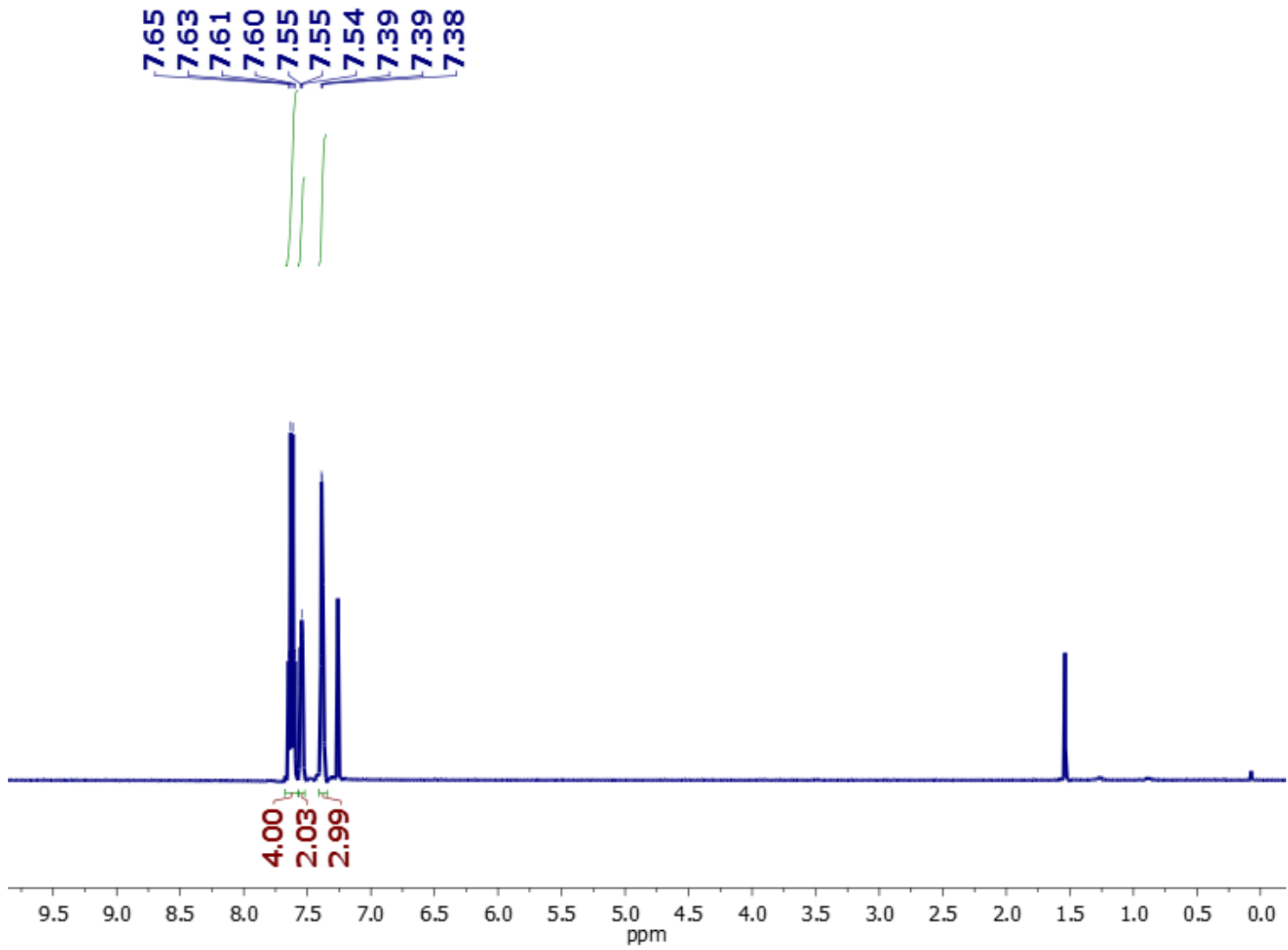

Figure S19. ${ }^{1} \mathrm{H}$ NMR spectrum of 4-(phenylethynyl)benzonitrile $\left(\mathrm{CDCl}_{3}, 500 \mathrm{MHz}\right)$. 


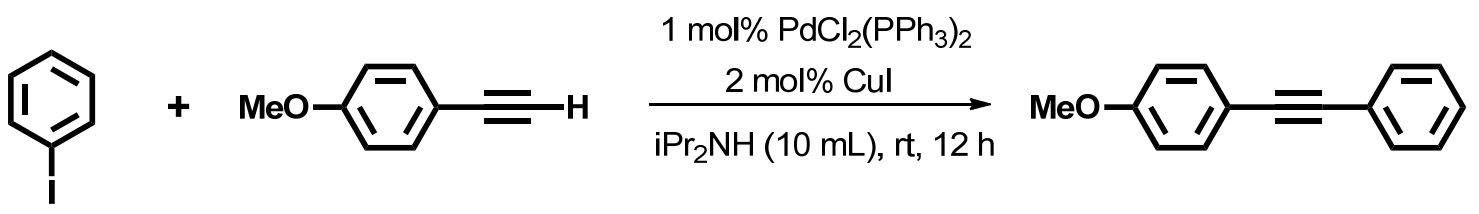

A $10 \mathrm{~mL} i \mathrm{Pr}_{2} \mathrm{NH}$ solution containing $\mathrm{PdCl}_{2}\left(\mathrm{PPh}_{3}\right)_{2}$ (16 mg, $\left.0.0226 \mathrm{mmol}\right), \mathrm{CuI}(9 \mathrm{mg}, 0.045$ mmol) and iodobenzene (463 mg, $254 \mu \mathrm{L}, 2.26 \mathrm{mmol}$ ) was degassed using $\mathrm{N}_{2}$ for 20 minutes in a $50 \mathrm{~mL}$ Schlenk flask equipped with a stir bar. 4-methoxyphenylacetylene (300 mg, 2.26 mmol) was added to the reaction mixture in two portions over the course of 30 minutes and the contents of the flask were stirred under a steady stream of nitrogen for $12 \mathrm{~h}$. The reaction mixture was filtered through a plug of silica by washing with hexanes $(2 \times 50 \mathrm{~mL})$. The orange solution was then dried in vacuo and purified using column chromatography $\left(1 \% \mathrm{Et}_{2} \mathrm{O}\right.$ in hexanes as the eluting mixture). Yield $=346 \mathrm{mg}(73 \%)$.

${ }^{1} \mathrm{H} \mathrm{NMR}\left(\mathrm{CDCl}_{3}, 500 \mathrm{MHz}\right)$ ppm: 7.52 (d, $\left.J=7.2 \mathrm{~Hz}, 2 \mathrm{H}\right), 7.48(\mathrm{~d}, J=8.5 \mathrm{~Hz}, 2 \mathrm{H}), 7.37-$ $7.29(\mathrm{~m}, 3 \mathrm{H}), 6.88(\mathrm{~d}, J=8.6 \mathrm{~Hz}, 2 \mathrm{H}), 3.83(\mathrm{~s}, 3 \mathrm{H}){ }^{4}$

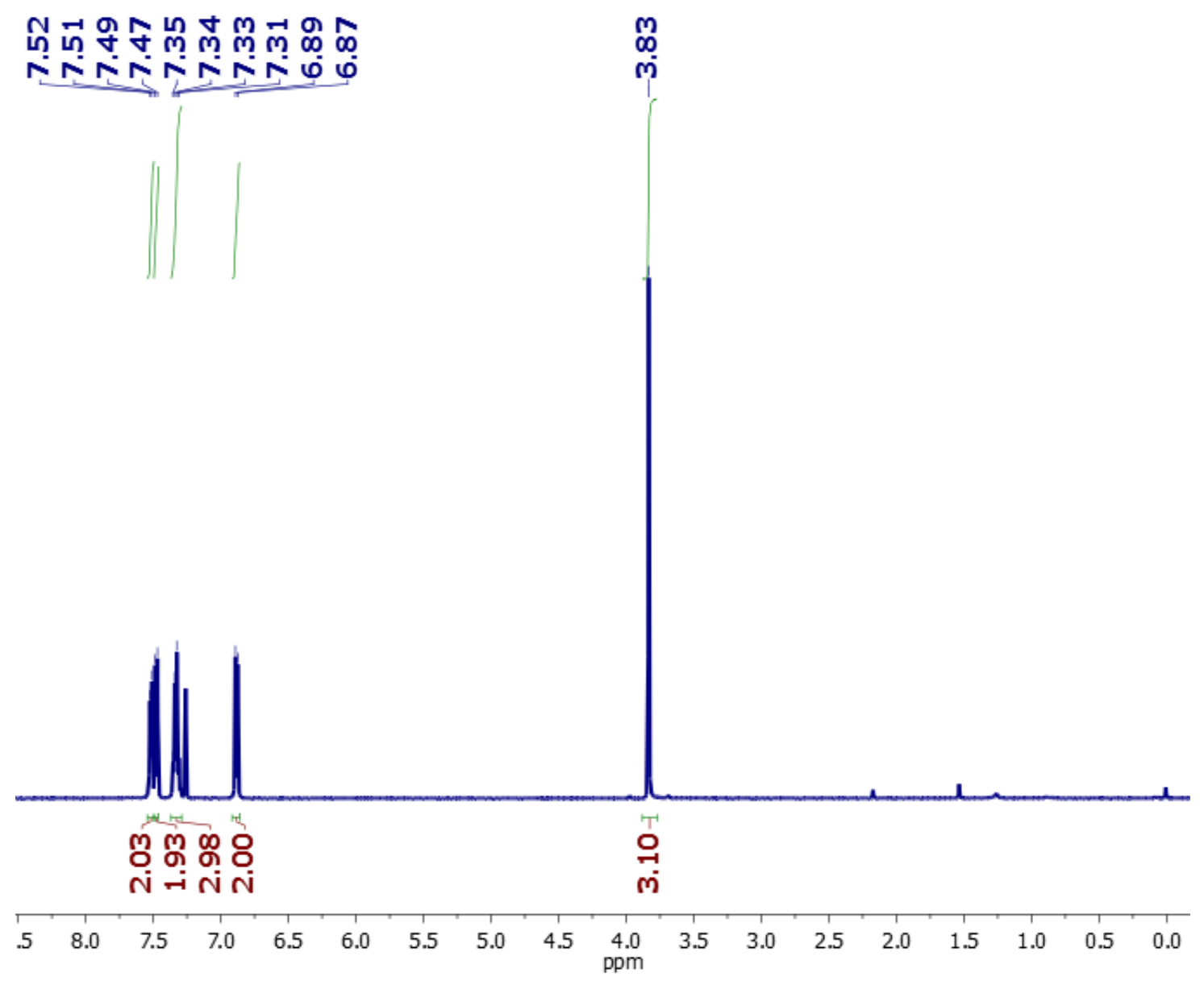

Figure S20. ${ }^{1} \mathrm{H}$ NMR spectrum of 1-methoxy-4-(phenylethynyl)benzene $\left(\mathrm{CDCl}_{3}, 500 \mathrm{MHz}\right)$. 


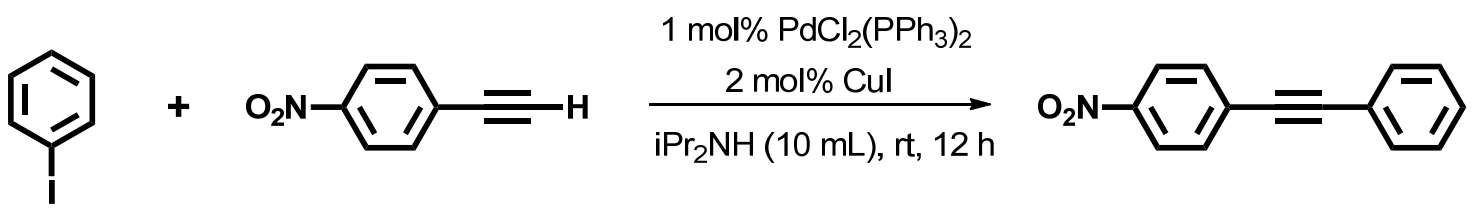

A $10 \mathrm{~mL} i \mathrm{Pr}_{2} \mathrm{NH}$ solution containing $\mathrm{PdCl}_{2}\left(\mathrm{PPh}_{3}\right)_{2}$ (24 mg, $\left.0.0339 \mathrm{mmol}\right), \mathrm{CuI}$ (13 mg, 0.067 $\mathrm{mmol}$ ) and iodobenzene (693 $\mathrm{mg}, 380 \mu \mathrm{L}, 3.39 \mathrm{mmol}$ ) was degassed using $\mathrm{N}_{2}$ for 20 minutes in a $50 \mathrm{~mL}$ Schlenk flask equipped with a stir bar. 4-nitrophenylacetylene (500 mg, 3.39 $\mathrm{mmol}$ ) was added to the reaction mixture in two portions over the course of 30 minutes and the contents of the flask were stirred under a steady stream of nitrogen for $12 \mathrm{~h}$. The reaction mixture was filtered through a plug of silica by washing with hexanes $(2 \times 50 \mathrm{~mL})$. The orange solution was then dried in vacuo and purified using column chromatography $(2.5 \%$ EtOAc in hexanes as the eluting mixture). Yield $=550 \mathrm{mg}(73 \%)$.

${ }^{1} \mathrm{H} \mathrm{NMR}\left(\mathrm{CDCl}_{3}, 500 \mathrm{MHz}\right)$ ppm: 8.23 (d, $\left.J=8.5 \mathrm{~Hz}, 2 \mathrm{H}\right), 7.67$ (d, $\left.J=8.6 \mathrm{~Hz}, 2 \mathrm{H}\right), 7.60-$ $7.54(\mathrm{~m}, 2 \mathrm{H}), 7.42-7.35(\mathrm{~m}, 3 \mathrm{H}){ }^{5}$
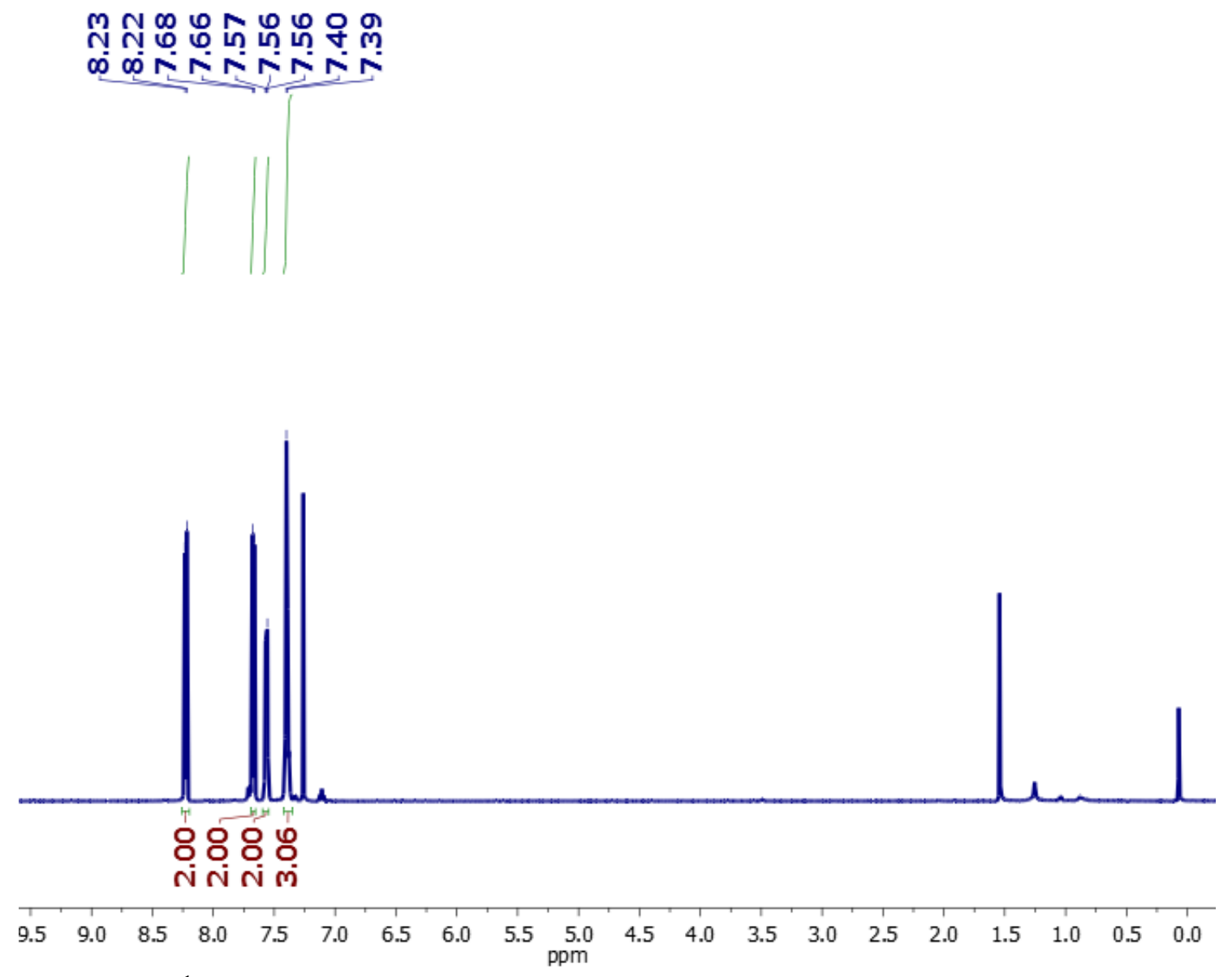

Figure S21. ${ }^{1} \mathrm{H}$ NMR spectrum of 1-nitro-4-(phenylethynyl)benzene $\left(\mathrm{CDCl}_{3}, 500 \mathrm{MHz}\right)$ 


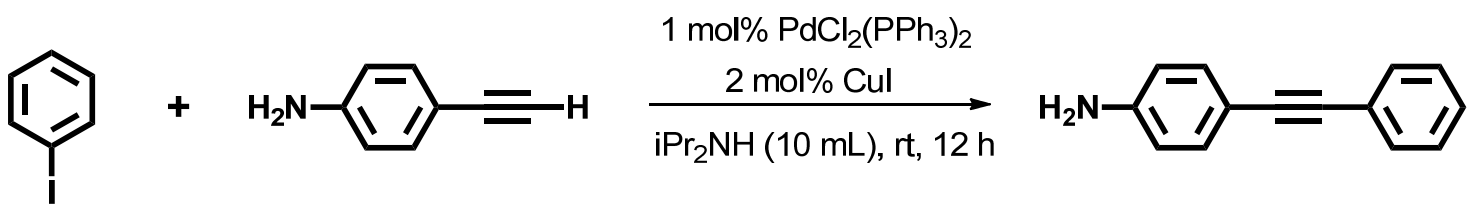

A $10 \mathrm{~mL} i \mathrm{Pr}_{2} \mathrm{NH}$ solution containing $\mathrm{PdCl}_{2}\left(\mathrm{PPh}_{3}\right)_{2}(30 \mathrm{mg}, 0.0426 \mathrm{mmol}), \mathrm{CuI}$ (16 mg, 0.085 $\mathrm{mmol}$ ) and iodobenzene ( $871 \mathrm{mg}, 478 \mu \mathrm{L}, 4.26 \mathrm{mmol}$ ) was degassed using $\mathrm{N}_{2}$ for 20 minutes in a $50 \mathrm{~mL}$ Schlenk flask equipped with a stir bar. 4-aminophenylacetylene (500 mg, 4.26 $\mathrm{mmol}$ ) was added to the reaction mixture in two portions over the course of 30 minutes and the contents of the flask were stirred under a steady stream of nitrogen for $12 \mathrm{~h}$. The reaction mixture was filtered through a plug of silica by washing with hexanes $(2 \times 50 \mathrm{~mL})$. The orange solution was then dried in vacuo and purified using column chromatography (12.5\% EtOAc in hexanes as the eluting mixture). Yield $=410 \mathrm{mg}(50 \%)$.

${ }^{1} \mathrm{H}$ NMR (C6 $\left.\mathrm{D}_{6}, 400 \mathrm{MHz}\right)$ ppm: 7.60-7.50 (m, 2H), 7.45-7.37 (m, 2H), 7.03-6.94 (m, 3H), $2.73(\mathrm{bs}, 2 \mathrm{H}){ }^{3}$

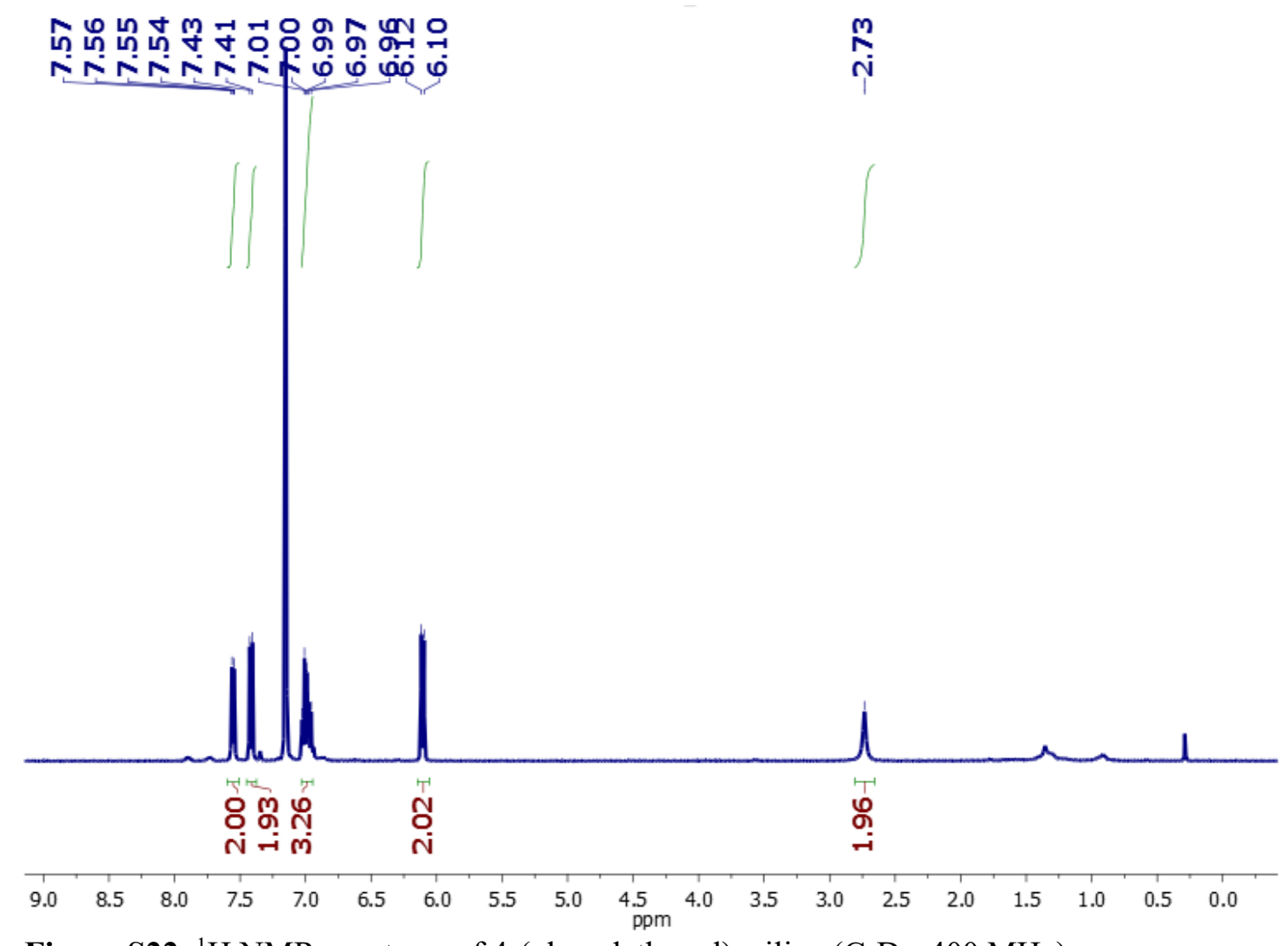

Figure S22. ${ }^{1} \mathrm{H}$ NMR spectrum of 4-(phenylethynyl)aniline $\left(\mathrm{C}_{6} \mathrm{D}_{6}, 400 \mathrm{MHz}\right)$. 


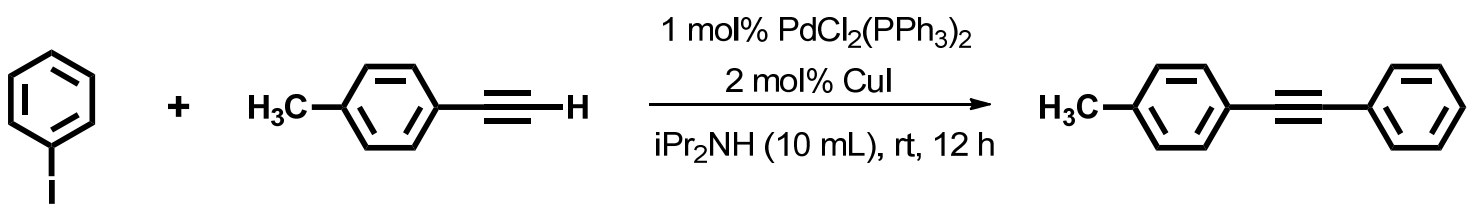

A $10 \mathrm{~mL} i \mathrm{Pr}_{2} \mathrm{NH}$ solution containing $\mathrm{PdCl}_{2}\left(\mathrm{PPh}_{3}\right)_{2}(27.6 \mathrm{mg}, 0.0393 \mathrm{mmol}), \mathrm{CuI}(15 \mathrm{mg}$, $0.0786 \mathrm{mmol}$ ) and iodobenzene ( $802 \mathrm{mg}, 440 \mu \mathrm{L}, 3.93 \mathrm{mmol}$ ) was degassed using $\mathrm{N}_{2}$ for 20 minutes in a $50 \mathrm{~mL}$ Schlenk flask equipped with a stir bar. 4-Ethynyltoluene (456 mg, 3.93 mmol) was added to the reaction mixture in two portions over the course of 30 minutes and the contents of the flask were stirred under a steady stream of nitrogen for $12 \mathrm{~h}$. The reaction mixture was filtered through a plug of silica by washing with hexanes $(2 \times 50 \mathrm{~mL})$. The orange solution was then dried in vacuo and purified using column chromatography (100\% hexanes as the eluting mixture). Yield $=423 \mathrm{mg}(56 \%)$.

${ }^{1} \mathrm{H}$ NMR $\left(\mathrm{CDCl}_{3}, 500 \mathrm{MHz}\right)$ ppm: 7.56-7.49 (m, 2H), 7.47-7.40 (m, 2H), 7.40-7.28 (m, 3H), 7.21-7.11(m, 2H), $2.38(\mathrm{~s}, 3 \mathrm{H}){ }^{6}$

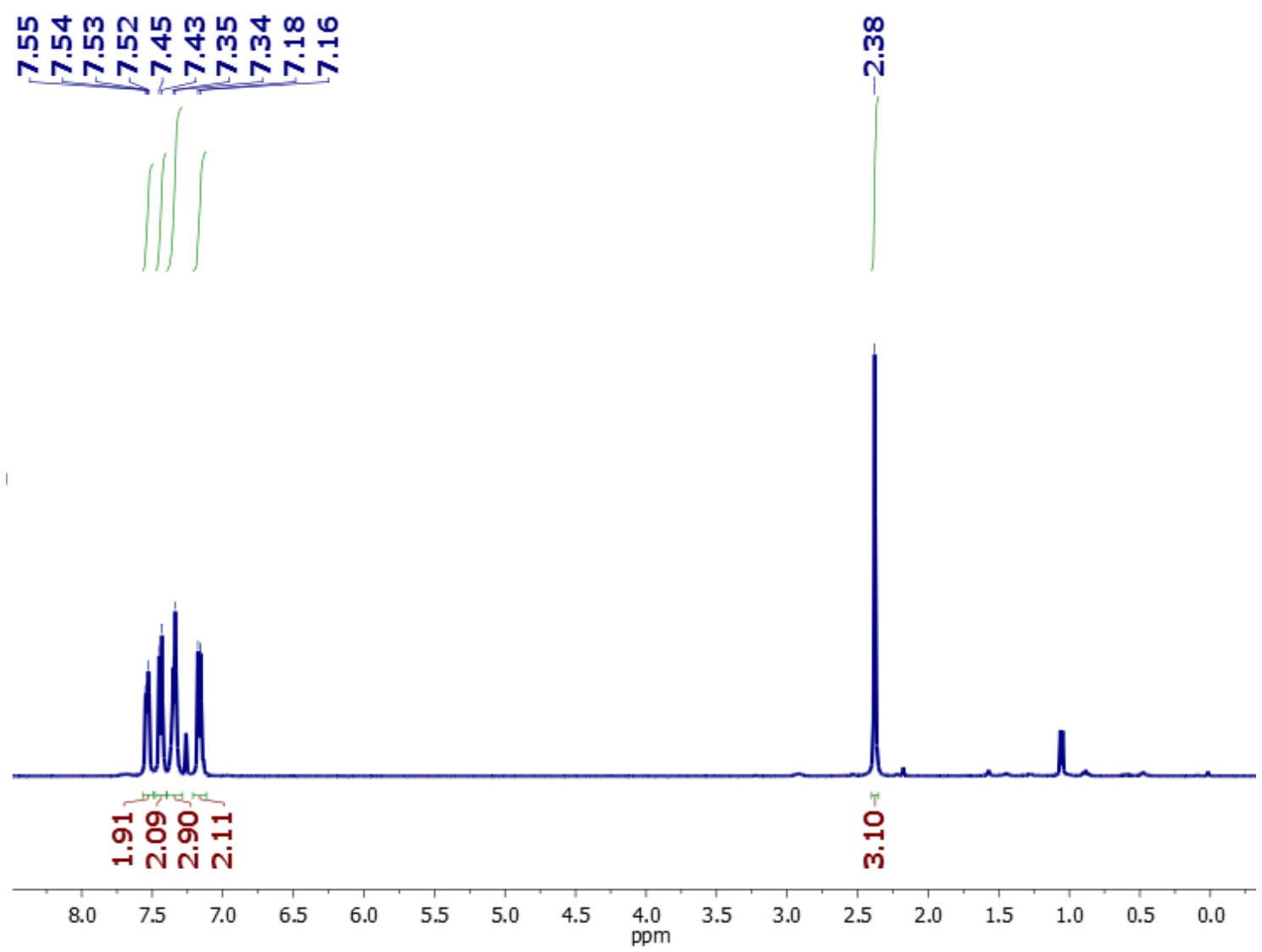

Figure S23. ${ }^{1} \mathrm{H}$ NMR spectrum of 1-methyl-4-(phenylethynyl)benzene $\left(\mathrm{CDCl}_{3}, 500 \mathrm{MHz}\right)$. 


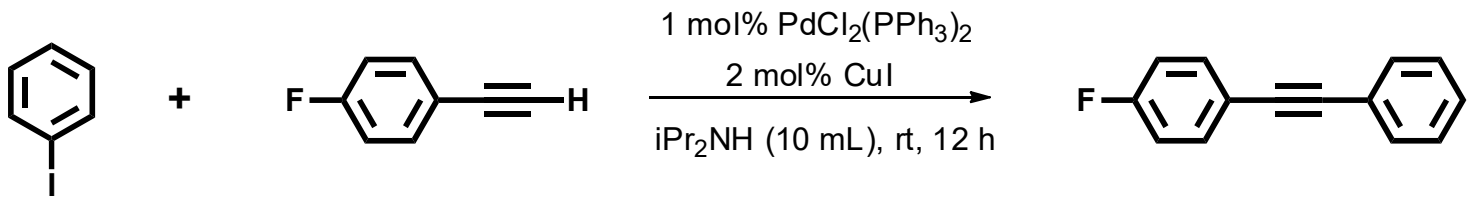

A $5 \mathrm{~mL} i \mathrm{Pr}_{2} \mathrm{NH}$ solution containing $\mathrm{PdCl}_{2}\left(\mathrm{PPh}_{3}\right)_{2}(13.8 \mathrm{mg}, 0.0197 \mathrm{mmol}), \mathrm{CuI}(7.5 \mathrm{mg}$, $0.0393 \mathrm{mmol}$ ) and iodobenzene (401 $\mathrm{mg}, 220 \mu \mathrm{L}, 1.97 \mathrm{mmol}$ ) was degassed using $\mathrm{N}_{2}$ for 20 minutes in a $50 \mathrm{~mL}$ Schlenk flask equipped with a stir bar. 1-Ethynyl-4-fluorobenzene (456 $\mathrm{mg}, 3.93 \mathrm{mmol}$ ) was added to the reaction mixture in two portions over the course of 30 minutes and the contents of the flask were stirred under a steady stream of nitrogen for $12 \mathrm{~h}$. The reaction mixture was filtered through a plug of silica by washing with hexanes $(2 \times 25$ $\mathrm{mL})$. The orange solution was then dried in vacuo and purified using column chromatography $(100 \%$ hexanes as the eluting mixture). Yield $=201 \mathrm{mg}(52 \%)$.

${ }^{1} \mathrm{H} \mathrm{NMR}\left(\mathrm{CDCl}_{3}, 500 \mathrm{MHz}\right) \mathrm{ppm}: 7.56-7.47(\mathrm{~m}, 4 \mathrm{H}), 7.38-7.31(\mathrm{~m}, 3 \mathrm{H}), 7.05(\mathrm{t}, J=8.4 \mathrm{~Hz}$, $3 \mathrm{H}) .{ }^{19} \mathrm{~F} \mathrm{NMR}\left(\mathrm{CDCl}_{3}, 470 \mathrm{MHz}\right) \mathrm{ppm}: 111(\mathrm{~m}, 1 \mathrm{~F}){ }^{7}$

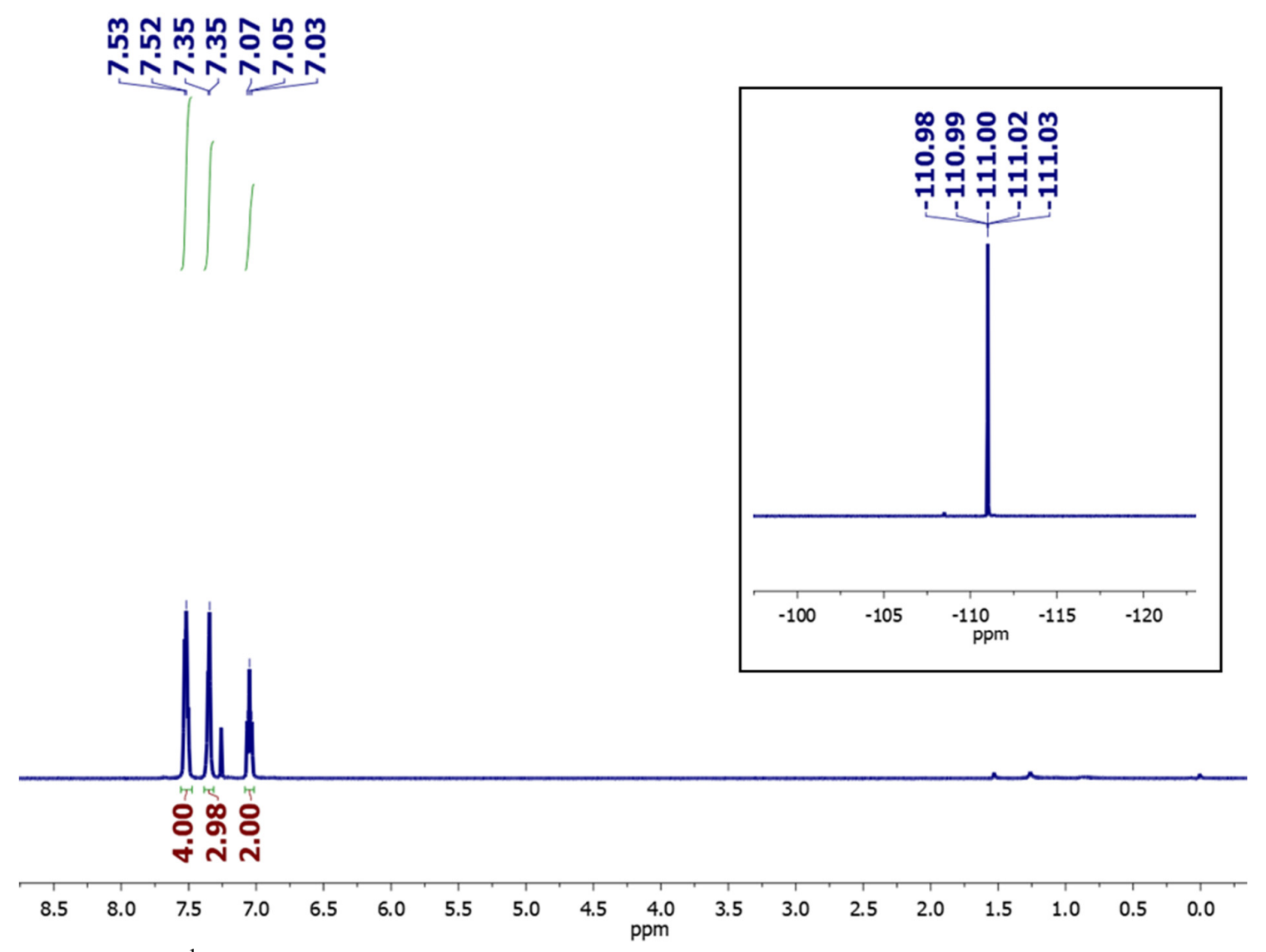

Figure S24. ${ }^{1} \mathrm{H}$ NMR spectrum of 1-fluoro-4-(phenylethynyl)benzene $\left(\mathrm{CDCl}_{3}, 500 \mathrm{MHz}\right)$. Inset shows ${ }^{19} \mathrm{~F}$ NMR spectrum $\left(\mathrm{CDCl}_{3}, 470 \mathrm{MHz}\right)$. 


\section{Synthesis of Z-stilbene- $d_{2}$}

$Z$-stilbene- $\mathrm{d}_{2}$ was prepared using $\mathrm{D}_{2} \mathrm{O}$ and diphenylacetylene by following published protocol. ${ }^{8}$

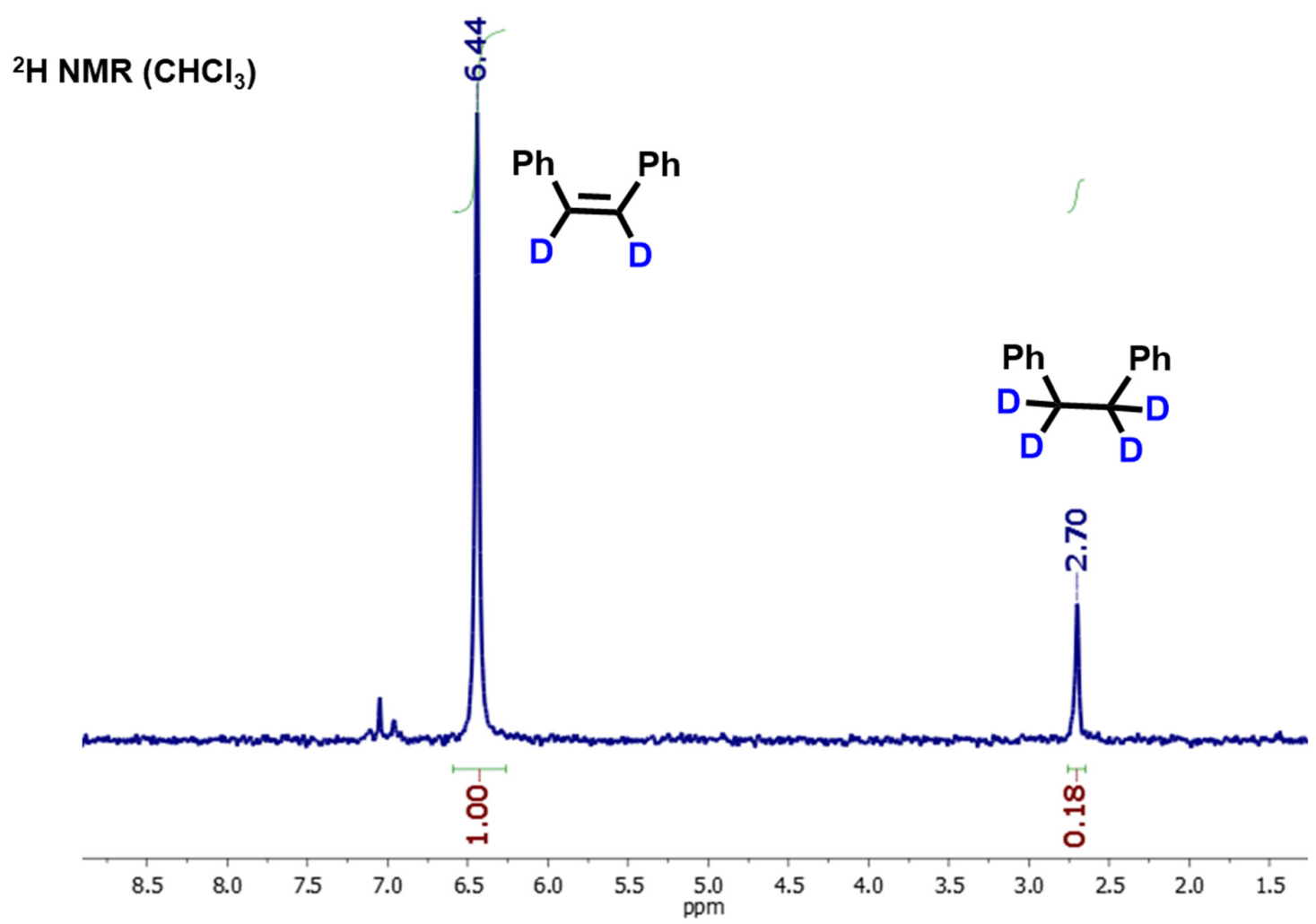

Figure S25. ${ }^{2} \mathrm{H}$ NMR spectrum $\left(\mathrm{CHCl}_{3}, 61.4 \mathrm{MHz}\right)$ of $Z$-stilbene- $d_{2}$ indicates $10 \%$ bibenzyl impurity. Small amounts of $E$-stilbene- $d_{2}$ was also observed. 


\section{SI References}

(1) Güsten, H.; Klasinc, L.; Kramer, V.; Marsel, J. Mass spectra of monosubstituted trans-stilbenes. $\begin{array}{lllll}\text { Organic Mass } & \text { Spectrometry } & 1974, & 8, & 323-334 .\end{array}$ https://onlinelibrary.wiley.com/doi/abs/10.1002/oms.1210080135

(2) Davis-Gilbert, Z. W.; Wen, X.; Goodpaster, J. D.; Tonks, I. A. Mechanism of Ti-Catalyzed Oxidative Nitrene Transfer in [2+2+1] Pyrrole Synthesis from Alkynes and Azobenzene. J. Am. Chem. Soc. 2018, 140, 7267-7281. https://doi.org/10.1021/jacs.8b03546

(3) Fu, S.; Chen, N.-Y.; Liu, X.; Shao, Z.; Luo, S.-P.; Liu, Q. Ligand-Controlled Cobalt-Catalyzed Transfer Hydrogenation of Alkynes: Stereodivergent Synthesis of Z- and E-Alkenes. J. Am. Chem. Soc. 2016, 138, 8588-8594. http://dx.doi.org/10.1021/jacs.6b04271

(4) Wardrop, D. J.; Komenda, J. P. Dehydrative Fragmentation of 5-Hydroxyalkyl-1H-tetrazoles: A Mild Route to Alkylidenecarbenes. Org. Lett. 2012, 14, 1548-1551. https://doi.org/10.1021/ol300276p

(5) Deol, H.; Pramanik, S.; Kumar, M.; Khan, I. A.; Bhalla, V. Supramolecular Ensemble of a TICT-AIEE Active Pyrazine Derivative and CuO NPs: A Potential Photocatalytic System for Sonogashira Couplings. ACS Catal. 2016, 6, 3771-3783. https://doi.org/10.1021/acscatal.6b00393

(6) Jin, G.; Zhang, X.; Cao, S. Transition-Metal-Free Sonogashira-Type Cross-Coupling of Alkynes with Fluoroarenes. Org. Lett. 2013, 15, 3114-3117. https://doi.org/10.1021/ol401317m

(7) Cai, R.; Lu, M.; Aguilera, E. Y.; Xi, Y.; Akhmedov, N. G.; Petersen, J. L.; Chen, H.; Shi, X. LigandAssisted Gold-Catalyzed Cross-Coupling with Aryldiazonium Salts: Redox Gold Catalysis without an External Oxidant. Angew. Chem. Int. Ed. 2015, 54, 8772-8776. https://onlinelibrary.wiley.com/doi/abs/10.1002/anie.201503546

(8) Zhao, C.-Q.; Chen, Y.-G.; Qiu, H.; Wei, L.; Fang, P.; Mei, T.-S. Water as a Hydrogenating Agent: Stereodivergent Pd-Catalyzed Semihydrogenation of Alkynes. Org. Lett. 2019, 21, 1412-1416. https://doi.org/10.1021/acs.orglett.9b00148 